\title{
WDR81 Is Necessary for Purkinje and Photoreceptor Cell Survival
}

\author{
Maria Traka, ${ }^{1}$ Kathleen J. Millen, ${ }^{2}$ Devon Collins, ${ }^{1}$ Benayahu Elbaz, ${ }^{1}$ Grahame J. Kidd, ${ }^{3}$ Christopher M. Gomez, ${ }^{1}$ and \\ Brian Popko ${ }^{1}$ \\ ${ }^{1}$ Department of Neurology, University of Chicago Center for Peripheral Neuropathy, University of Chicago, Chicago, Illinois 60637, ${ }^{2}$ Division of Genetic \\ Medicine, Department of Pediatrics, University of Washington, Center for Integrative Brain Research, Seattle Children's Hospital, Seattle, Washington \\ 98105, and ${ }^{3}$ Department of Neurosciences, Lerner Research Institute, Cleveland Clinic, Cleveland, Ohio 44195
}

The gene encoding the WD repeat-containing protein 81 (WDR81) has recently been described as the disease locus in a consanguineous family that suffers from cerebellar ataxia, mental retardation, and quadrupedal locomotion syndrome (CAMRQ2). Adult mice from the $\mathrm{N}$-ethyl- $\mathrm{N}$-nitrosourea-induced mutant mouse line nur5 display tremor and an abnormal gait, as well as Purkinje cell degeneration and photoreceptor cell loss. We have used polymorphic marker mapping to demonstrate that affected nur5 mice carry a missense mutation, L1349P, in the Wdr81 gene. Moreover, homozygous nur5 mice that carry a wild-type Wdr81 transgene are rescued from the abnormal phenotype, indicating that $W d r 81$ is the causative gene in nur5. WDR81 is expressed in Purkinje cells and photoreceptor cells, among other CNS neurons, and like the human mutation, the nur 5 modification lies in the predicted major facilitator superfamily domain of the WDR81 protein. Electron microscopy analysis revealed that a subset of mitochondria in Purkinje cell dendrites of the mutant animals displayed an aberrant, large spheroid-like structure. Moreover, immunoelectron microscopy and analysis of mitochondrial-enriched cerebellum fractions indicate that WDR81 is localized in mitochondria of Purkinje cell neurons. Because the nur5 mouse mutant demonstrates phenotypic similarities to the human disease, it provides a valuable genetic model for elucidating the pathogenic mechanism of the WDR81 mutation in CAMRQ2.

\section{Introduction}

The cerebellum is a crucial structure required for proper motor coordination and balance. Cerebellar atrophy characterizes most hereditary cerebellar ataxias and is commonly caused by the death of Purkinje cells, the sole efferent projection neurons of the cerebellar cortex, resulting in the functional impairment of the cerebellum. Clinical symptoms include impaired motor coordination, poor balance, tremor, oculomotor deficits, dysarthria, and abnormal gait and posture. Although evidence for a genetic locus is usually available (Fogel and Perlman, 2007; Soong and Paulson, 2007), the pathological mechanisms that cause Purkinje cell degeneration and death in these diseases remain largely unknown.

\footnotetext{
Received May 17, 2012; revised Jan. 3, 2013; accepted Feb. 19, 2013.

Author contributions: M.T. and B.P. designed research; M.T., D.C., and B.E. performed research; M.T., K.J.M., D.C., B.E., G.J.K., C.M.G., and B.P. analyzed data; M.T. wrote the paper.

This work was supported in part by an award from the Myelin Repair Foundation. M.T. was supported by a National Multiple Sclerosis Society postdoctoral fellowship award. We thank Dr. Monica Justice for providing the ENU-induced nur 5 mutant mouse line; Erdong Liu, Shelby Lane, Kavin Arasi, Ani Solanki, Yimei Chen, and Hanson Ho for skillful technical assistance; Gloria Wright for helping us prepare the figures; Dr. Robert Wollmann for expert advice on the nur5 mutant pathology; Dr. Thomas G. Hampton (Mouse Specifics Inc) for help with DigiGait analysis; Darlene S. Douglas for critical comments on the manuscript; Andrew Roholt and Emily Benson (Renovo Neural Inc) for assistance with serial block face scanning electron microscopy analysis; and Kristen Wroblewski, Dr. Theodore Karrison, and Dr. Sydeaka Watson (Biostatistics Laboratory at the University of Chicago) for help with statistical analysis.

The authors declare no competing financial interests.

Correspondence should be addressed to Dr. Brian Popko, Department of Neurology, University of Chicago, 5841 South Maryland Avenue, MC2030, Chicago, IL 60637. E-mail: bpopko@uchicago.edu.

DOI:10.1523/JNEUROSCI.2394-12.2013

Copyright $\odot 2013$ the authors $\quad 0270-6474 / 13 / 336834-11 \$ 15.00 / 0$
}

Recently, the WDR81 missense mutation P856L, which lies in the major facilitator superfamily (MFS) domain of the protein, was identified in members of a consanguineous family in Turkey who suffer from CAMRQ2 (Gulsuner et al., 2011), a rare form of autosomal recessive cerebellar ataxia also known as Uner Tan syndrome (Tan, 2006), which is associated with cerebellar hypoplasia, severe mental retardation, and quadrupedal gait. Although WDR81 is likely a transmembrane protein that contains a MFS domain, which characterizes solute carrier transport proteins (Pao et al., 1998), flanked by a BEACH domain (De Lozanne, 2003) at the $\mathrm{N}$ terminus and six WD repeats at the $\mathrm{C}$ terminus (Li and Roberts, 2001), its cellular function has not been described.

$\mathrm{N}$-ethyl- $\mathrm{N}$-nitrosourea (ENU) mutagenesis offers the opportunity to study specific disease phenotypes without any previous knowledge of the genetic basis of the disease (Acevedo-Arozena et al., 2008). This forward genetics approach involves the positional cloning of mutated genetic loci and enables the identification of genes that, via functional characterization, may provide insight into the underlying disease mechanism. Here, we characterized a missense mutation in the MFS domain of the WDR81 protein, L1349P, that causes Purkinje cells loss leading to cerebellar ataxia and cerebellar atrophy in the ENU-induced, autosomal recessive mouse mutant nur5 (Kile et al., 2003). Additionally, the nur5 mouse displays severe photoreceptor cell loss that begins early postnatally and progresses throughout adulthood. Our data showed that WDR81 is expressed in Purkinje cells and photoreceptor cells among other CNS neurons and is localized in mito- 
Table 1. Gait dynamics in nur5 heterozygous (control) and homozygous (mutant) mice at $\mathrm{P} 60^{a}$

\begin{tabular}{|c|c|c|c|c|c|c|}
\hline \multirow[b]{2}{*}{ Gait index } & \multicolumn{3}{|l|}{ Left side } & \multicolumn{3}{|l|}{ Right side } \\
\hline & Control $(n=3)$ & Mutant $(n=4)$ & $p$ & Control $(n=3)$ & Mutant $(n=4)$ & $p$ \\
\hline Swing duration (ms) & $90 \pm 20$ & $60 \pm 0$ & 0.015 & $100 \pm 10$ & $70 \pm 10$ & 0.001 \\
\hline Stride frequency $(\mathrm{Hz})$ & $4.02 \pm 0.13$ & $5.54 \pm 0.35$ & $<0.001$ & $4.01 \pm 0.24$ & $5.41 \pm 0.62$ & 0.014 \\
\hline Paw area Variability $\left(\mathrm{cm}^{2}\right)$ & $0.04 \pm 0.01$ & $0.09 \pm 0.01$ & $<0.001$ & $0.03 \pm 0.02$ & $0.06 \pm 0.01$ & 0.045 \\
\hline Number of steps & $10.56 \pm 0.82$ & $15.67 \pm 1.50$ & 0.003 & $9.36 \pm 2.80$ & $14.60 \pm 1.74$ & 0.027 \\
\hline
\end{tabular}

${ }^{a}$ Data are mean \pm SD. Only indices that are statistically significant $(p<0.05$, two-tailed unpaired Student's $t$ test) in both left and right hindlimbs between the two groups are shown.

Table 2. Stance width variability in nur5 heterozygous (control) and homozygous (mutant) mice at $\mathrm{P} \mathrm{O}^{a}$

\begin{tabular}{llcl}
\hline & Control $(n=3)$ & Mutant $(n=4)$ & $p$ \\
\hline Stance width variability $(\mathrm{cm})^{b}$ & $0.14 \pm 0.01$ & $0.26 \pm 0.06$ & 0.026 \\
Stance width CV (\%) $^{b}$ & $5.53 \pm 0.69$ & $10.67 \pm 3.03$ & 0.037 \\
\hline
\end{tabular}

${ }^{a}$ Data are mean \pm SD. Differences in means between the two groups are statistically significant $(p<0.05$, twotailed unpaired Student's t test).

${ }^{b}$ Stance width variability and CV require the calculation of the width (distance between left and right hindlimb) for the set of strides recorded from each mouse.

chondria of Purkinje cell neurons. Furthermore, we demonstrate that Purkinje cell loss in nur5 mutants is associated with the presence of large spheroid-like mitochondria that display cristae disorganization and a frequently disrupted outer membrane. The nur5 mutant mice thus provide a valuable tool for the study of WDR81 function, as well as an authentic genetic model for the study of the autosomal recessive cerebellar ataxia CAMRQ2.

\section{Materials and Methods}

Mice. Nur5 (Kile et al., 2003) heterozygous mice on the C57BL/6J background, which are also carriers of the inversion $\operatorname{Inv}(11) 8 \mathrm{Brd}^{\text {Trp53-Wnt3 }}$ balancer that marks the non-ENU mutagenized chromosome 11, were provided by Dr. Monica Justice (Baylor College of Medicine, Houston, TX). Both male and female mice were used. All animal studies were conducted in compliance with the University of Chicago's Animal Care and Use Committee guidelines.

Gait analysis. Gait dynamics and posture were analyzed by using the DigiGait imaging system (Mouse Specifics) as previously described (Hampton et al., 2011). The mice were allowed to walk on the transparent treadmill at a speed of $20 \mathrm{~cm} / \mathrm{s}$, and $\sim 2 \mathrm{~s}$ of video images of the ventral view of each mouse was acquired to calculate 37 different gait indices for each left and right hindlimb. Definitions of parameters shown in Tables 1 and 2 are as follows: swing duration (no paw contact with the belt), stride duration (total stance and swing duration), propulsion duration (decreasing paw contact area over time), stance width variability (the SD of the stance width for the set of strides recorded), stride frequency (the number of strides per second), stance width CV $(100 \times$ stance width variability normalized to the mean), paw area variability (the SD of the paw area for the set of strides recorded), and number of steps (the total number of strides used to calculate the gait parameters, as recorded in $2 \mathrm{~s}$ of video images).

Gene mapping. Nur5 homozygous males were outcrossed to BALB/cJ females to produce F1 nur5 heterozygotes, which were backcrossed to nur5 homozygous males to obtain N2 nur5 homozygous (affected) and heterozygous (unaffected) mice. Genomic DNA samples were genotyped via PCR amplification of simple sequence length polymorphism markers as previously described (Traka et al., 2008).

Sequence analysis. Genomic DNA from nur5 homozygous and agematched wild-type mice was used for amplifying all 10 exons of the mouse Wdr81 gene. Each PCR product was purified by the QIAquick PCR Purification Kit (QIAGEN) and sequenced in both directions with PCR primers. The sequences for all the primers used are available upon request.

Antibodies. The antibodies used were rabbit polyclonal antibody against GAPDH (Cell Signaling Technology), and mouse monoclonal antibodies against $\alpha$-actin (clone AC-40, Sigma), calbindin (clone CB955, Sigma), COX IV (ab33985, Abcam), and neuron-specific nuclear protein (NeuN, Millipore).

Generation of Wdr81-BAC transgenic mice. The mouse BAC clone MSMG01-261K4 DNA (Abe et al., 2004) was obtained from the RIKEN BRC DNA Bank (www.brc.riken.go.jp/lab), grown in DH5 $\alpha$ cells (Invitrogen) and purified with the Nucleobond BAC 100 kit (Clontech). The purified BAC's integrity was verified by restriction analysis. The DNA (circular plasmid) was dissolved in injection buffer $(10 \mathrm{~mm}$ Tris- $\mathrm{HCl}, \mathrm{pH}$ 7.5, $0.1 \mathrm{~mm}$ EDTA, $100 \mathrm{~mm} \mathrm{NaCl}, 30 \mu \mathrm{m}$ spermine, $70 \mu \mathrm{M}$ spermidine) and injected at a concentration of $4 \mathrm{ng} / \mu \mathrm{l}$ into fertilized mouse oocytes isolated from wild-type C57BL/6J females. The transgenic mice were identified by PCR genotyping using primers designed against the pBACe3.6 vector. The primer sequences used for genotyping are available upon request.

Rotarod. We measured the motor coordination and balance of the nur5 homozygous and their littermate heterozygous and Wdr81-BAC transgenic mice at P60 on the rotarod (Stoelting) in accelerating speed mode (5-45 rpm) as previously described (Traka et al., 2010). Both male and female mice were tested in each group.

WDR81 antibody production. The Wdr81 cDNA fragment 4761-4940 was amplified by RT-PCR from total RNA isolated from the cerebellum of an adult wild-type mouse, was cloned with the pGEM-T vector system (Promega), and was subcloned into the pGEX-T4-1 vector (GE Healthcare). The resultant GST-fused WDR81 peptide was used to immunize rabbits (Antagene), and the generated WDR81 antibody was purified using a peptide affinity column (Antagene). The primer sequences used for the RT-PCR are available upon request.

Histology, immunohistochemistry, and TEM. Histology, immunohistochemistry, and TEM were performed as previously described (Dupree et al., 1998; Traka et al., 2008). The immunoelectron microscopy protocol is available upon request. For TUNEL assays, either the ApopTag Peroxidase or Fluorescein In Situ Apoptosis Detection Kit (Millipore) was used according to the procedure described in the manufacturer's protocol.

Serial blockface scanning EM (3DEM). For 3DEM, P21 nur5 homozygous and heterozygous mice were perfused with $2.5 \%$ glutaraldehyde and $4 \%$ paraformaldehyde in a $0.1 \mathrm{~m}$ sodium cacodylate buffer, and the cerebellums were dissected, postfixed in the same fixative, and submitted to Renovo Neural Inc for 3DEM analysis. Briefly, $700 \mu \mathrm{m}$ of tissue from the midline extending laterally was used, and the third lobe of the cerebellum was dissected into three individual samples, which were stained with heavy metals (Deerinck et al., 2010), embedded in Epon resin, and mounted onto pins (detailed protocol available from Renovo Neural). Serial blockface images (analogous to serial sectioning) were obtained using a Zeiss Sigma VP scanning electron microscope equipped with a Gatan $3 \mathrm{View}$ in-chamber ultramicrotome. Purkinje cell bodies and their dendrites were initially identified, and regions of interest chosen that were $\sim 35 \mu \mathrm{m}$ distal from the Purkinje cell body layer. Series of 500 images were acquired at $2 \mathrm{kV}$ using at 15,000 magnification from the ROI, resulting in a field analysis of $40.93 \mu \mathrm{m} \times 40.93 \mu \mathrm{m}$ at $5 \mathrm{~nm}$ /pixel with $50 \mathrm{~nm}$ slices. Images were registered and resized as necessary using ImageJ/FIJI software (http://fiji.sc/). Five dendritic processes were randomly selected from each sample, and $10-15 \mu \mathrm{m}$ of these processes and mitochondria were traced using Reconstruct software (Fiala, 2005) as previously described (Ohno et al., 2011). Volume, length, branching, surface 
A

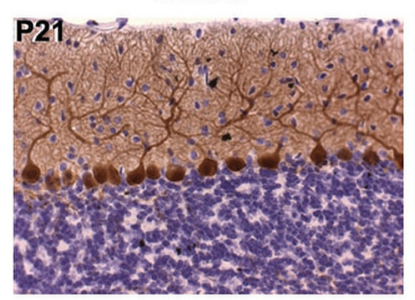

mutant

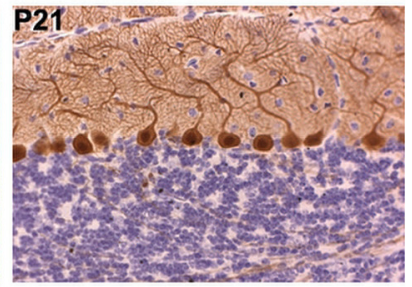

control

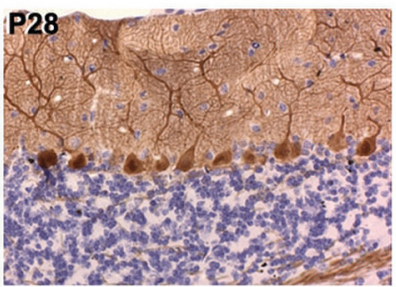

mutant

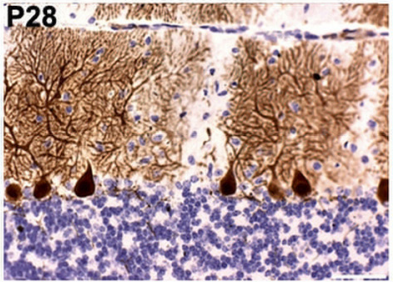

B
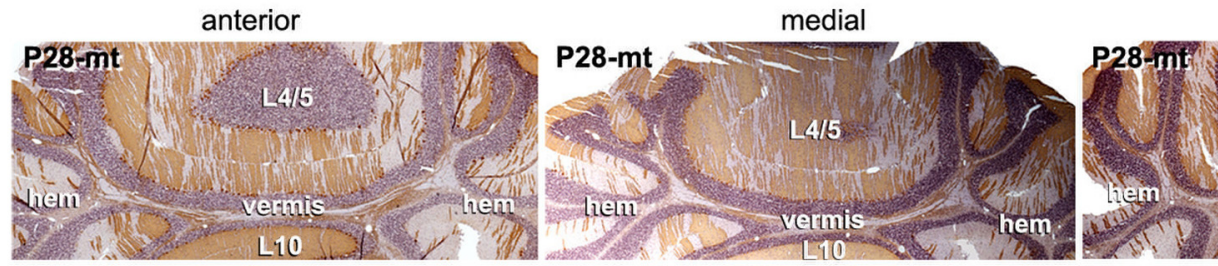

posterior

C
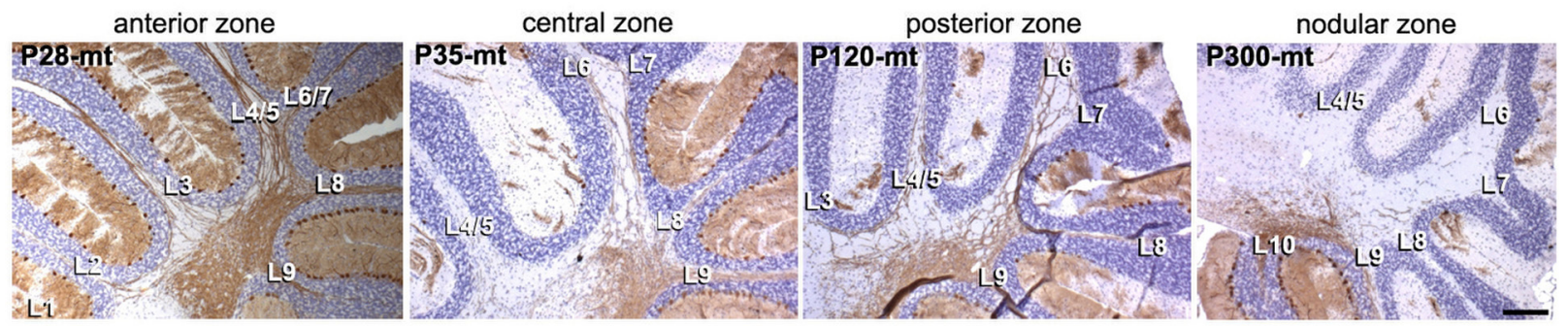

D

\section{P28-TUNEL contro}

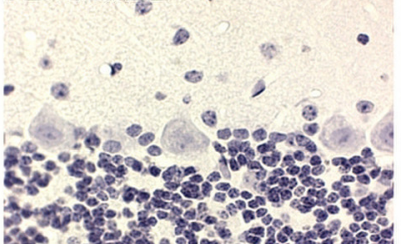

E

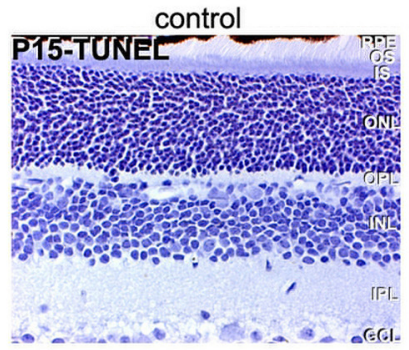

F

P28-cerebellum

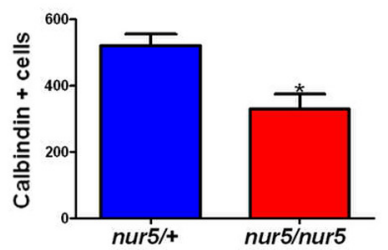

mutant

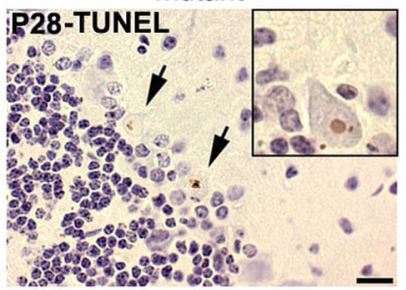

mutant

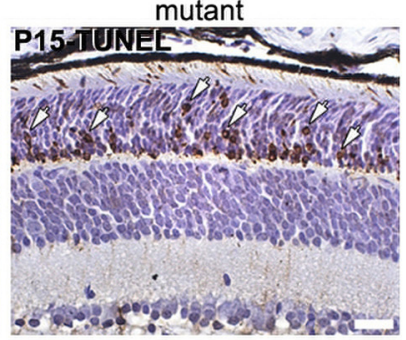

P15-retina

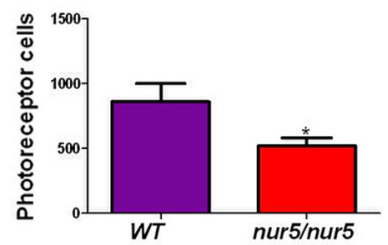

control

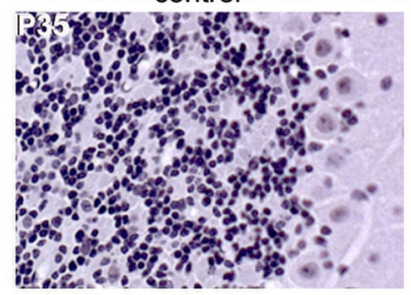

control

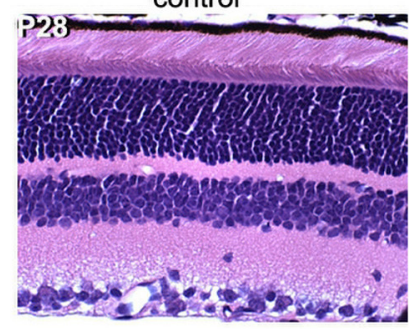

G

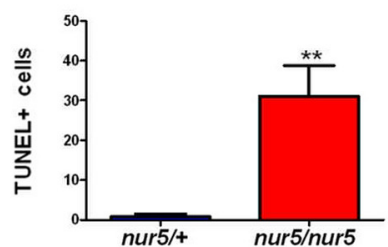

mutant

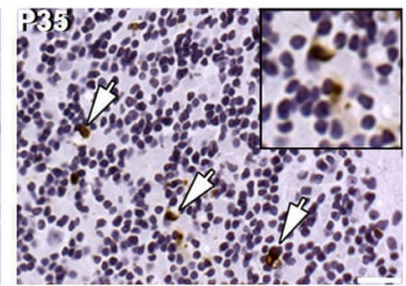

mutant

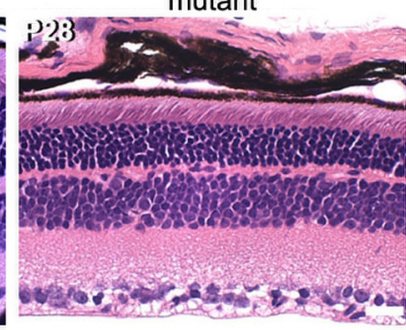

P15-retina

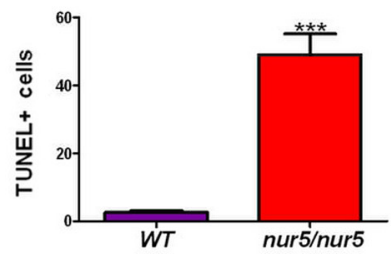

Figure 1. Purkinje cell and photoreceptor cell death in the nur 5 mutant. A, At P21, calbindin (brown) is similarly expressed in nur $5 /+$ (control) and nur $5 /$ nur 5 (mutant) mice, whereas at P28, the calbindin staining showed gaps in the molecular layer of nur 5 mutants compared with controls, indicating Purkinje cell death. $\boldsymbol{B}$, Loss of calbindin-stained Purkinje cells produces gaps organized in parasagittal stripes in the vermis ( $(4 / 5$, lobules $4 / 5)$ and the hemispheres (hem) on coronal sections from the anterior, medial, and posterior levels of the anterior cerebellar lobe in P28 mutants ( $\mathrm{mt}$ ), indicating a patterned Purkinje cell death. C, Loss of calbindin-stained Purkinje cells is observable in the anterior zone lobules L1-5 at P28, the central zone lobules L6 -7 at P35, the posterior zone lobule L8 at P120, and the nodular zone lobule L9 at P300. D, At P28, TUNEL-positive Purkinje cell nuclei (brown, arrows) were identified in the mutant mice. Inset, Higher magnification of a dying Purkinje cell. The nur5 mutants also showed TUNEL-positive nuclei in the granule cell layer at P35 (brown, arrows and higher magnification in the inset), whereas no TUNEL signal was detected in the cerebellar cortex of control animals. $E$, Although the mutant retina has a relatively normal laminar organization when observed in sections from P15 nur5 mutant mice, it contains many TUNEL-positive nuclei (brown, arrows) in the ONL, the layer formed by the photoreceptor cell bodies, indicating that photoreceptors are dying in these animals. Because of photoreceptor cell loss, the retina becomes much thinner in mutant mice at P28. $\boldsymbol{F}$, Counts of the calbindin-positive cells confirmed that Purkinje cells are significantly reduced in the cerebellum of the nur5/nur 5 mice versus the nur5/+ ones at P28, whereas counts of cell nuclei in 0NL showed fewer photoreceptors in the retina of nur $5 /$ nur 5 mice versus wild-type (Figure legend continues.) 
A

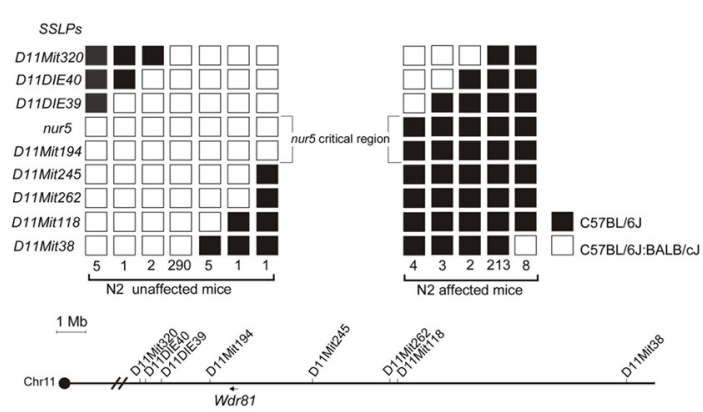

B

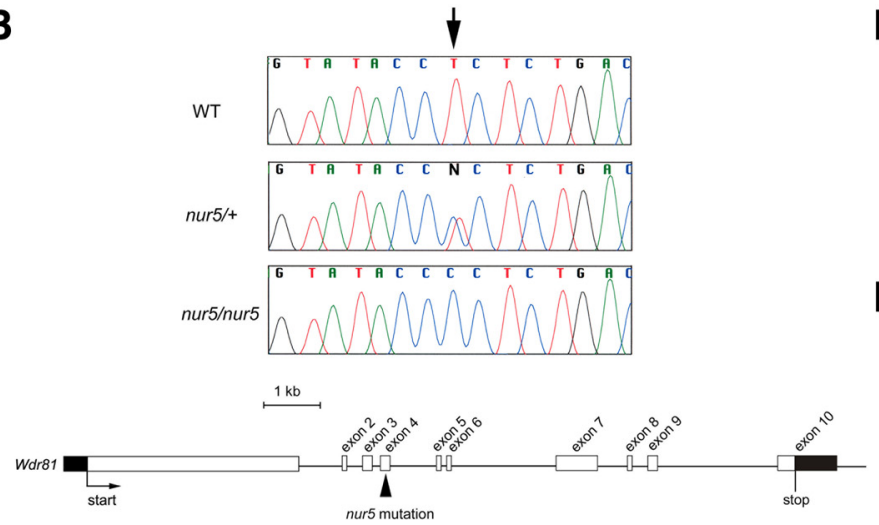

C

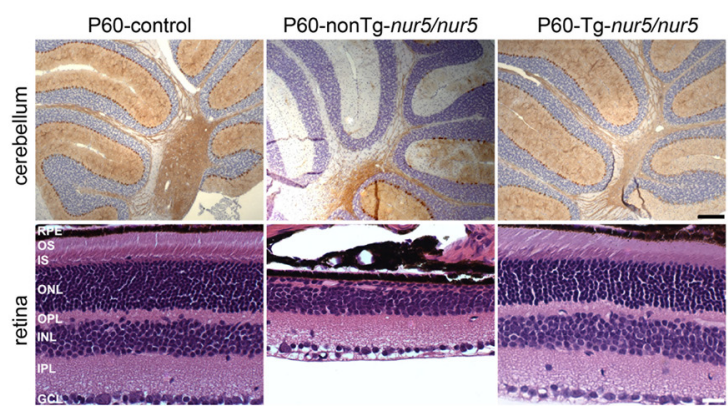

D
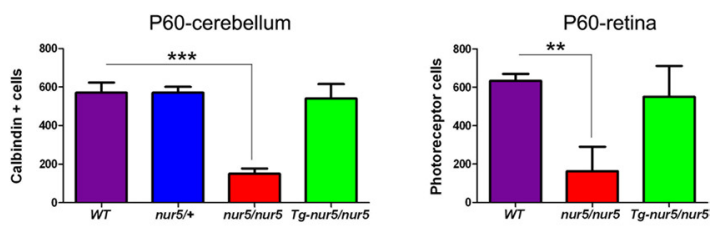

$\mathbf{E}$
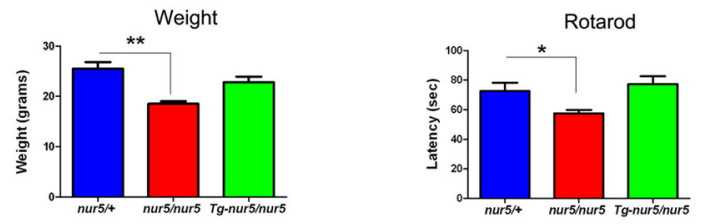

Figure 2. Mapping of the nur 5 mutation to the Wdr81 gene. $A$, Genotyping $535 \mathrm{~N} 2$ affected and unaffected mice for simple sequence length polymorphism markers (SSLPs; homozygous mutant background strain, black boxes; heterozygous, open boxes) determined that the critical region of the nur 5 mutation lay between the markers D11DIE39 and D11Mit245, an $\sim 5.46 \mathrm{Mb}$ region on the physical map. Sequencing all of the known genes annotated within the nur 5 critical region revealed the Wdr81 gene as the mutated locus in nur 5 mice. B, A T to C transition is present in the Wdr81 gene at the 4046 coding nucleotide (arrow) in exon 4 (arrowhead) of nur 5 heterozygous and homozygous mice compared with wild-type (WT) mice. C, Rescue of the nur 5 phenotype was observed in Wdr81 BAC transgenic Tg(MSMG01-261K4)12Pop (Tg) nur5/nur5 mice (Tg-nur5/nur5), which, in contrast to their nontransgenic nur5/nur5 littermates (nonTg-nur5/nur5), displayed normal Purkinje cell numbers as detected by calbindin staining (brown) of cerebellar sagittal sections and showed similar to normal photoreceptor cell numbers in the retina at P60. D, Counts of calbindin-positive cells showed significant loss of Purkinje cells in the cerebellum of the P60 nur5/nur5 mice and normal cells in nur5/+ and Tg-nur5/nur5 mice compared with WT animals. Cell nuclei counts in ONL layer showed significantly fewer photoreceptors in the retina of the P60 nur5/nur5 mice and normal cell numbers in Tg-nur5/nur5 mice compared with WT animals (mean \pm $\mathrm{SD} ; n=3$ mice per group). ${ }^{* *} p<0.01$ (one-way ANOVA followed by Dunnett's post hoc analysis test), ${ }^{* * *} p<0.001$ (one-way ANOVA followed by Dunnett's post hoc analysis test). $\boldsymbol{E}$, Weight loss observed in P60 nur $5 /$ nur 5 mice is rescued in the Tg-nur $5 /$ nur 5 mice compared with their nur $5 /+$ littermates (mean \pm SD; $n=15$ for nur $5 /+; n=7$ for nur $5 / n u r 5 ; n=$ 11 for Tg-nur5/nur5). ${ }^{* *} p<0.01$ (one-way ANOVA followed by Dunnett's post hoc analysis test). When tested on the rotarod, the P60 nur $5 /$ nur 5 mice showed significantly reduced latency ( ${ }^{*} p<0.05, n=7$ ), whereas the Tg-nur $5 /$ nur 5 mice were normal $(p>0.05, n=11$ ) compared with nur $5 /+$ mice (controls, $n=15)$. Data are mean \pm SD. A linear regression model with time as the dependent variable and weight and genotype as independent variables was fit. Because of the multiple groups being compared, Bonferroni adjusted $p$ values are reported. RPE, Retina pigment epithelium; OS, outer segment layer; IS, inner segment layer; ONL, outer nuclear layer; OPL, outer plexiform layer; INL, inner nuclear layer; IPL, inner plexiform layer; GCL, ganglion cell layer. Sections in C-cerebellum were counterstained with hematoxylin (blue), whereas sections in C-retina were stained with hematoxylin (blue) and eosin (pink). Scale bars: C (cerebellum), $200 \mu \mathrm{m}$; and C (retina), $20 \mu \mathrm{m}$.

area, and diameter were recorded for each mitochondrion and were statistically analyzed using RKWard software (http://rkward.sourceforge.net/). Reconstructed meshes were rendered using Blender software for final image production.

RT-PCR. Total RNA was extracted from the cerebellums of P21 $W d r 81^{\text {nur } 5}$ homozygous and heterozygous mice and adult (postnatal day 30 [P30]) wild-type mice using the TRIzol reagent (Invitrogen), and cDNA synthesis, RT-PCR, and real time qRT-PCR analysis were performed as previously described (Traka et al., 2008). Cyclophilin and Gapdh were used as internal control genes for RT-PCR and qRT-PCR

$\leftarrow$

(Figure legend continued.) (WT) mice at P15 (mean \pm SD; $n=3-5$ mice per group). ${ }^{*} p<0.05$ (two-tailed unpaired Student's $t$ test). $\mathbf{G}$, Increased numbers of TUNEL-positive nuclei were found in the cerebellum of the nur $5 /$ nur 5 mice versus nur $5 /+$ mice at $P 28$ and in the $0 N L$ of the retina of the nur $5 /$ nur5 mice versus the WT mice at $P 15$ (mean $\pm S D ; n=3-5$ mice per group). ${ }^{* *} p<0.01$ (two-tailed unpaired Student's $t$ test), ${ }^{* * *} p<0.001$ (two-tailed unpaired Student's $t$ test). L, Lobule; RPE, retina pigment epithelium; OS, outer segment layer; IS, inner segment layer; $0 \mathrm{NL}$, outer nuclear layer; $\mathrm{OPL}$, outer plexiform layer; INL, inner nuclear layer; IPL, inner plexiform layer; $\mathrm{GCL}$, ganglion cell layer. Sections in $\boldsymbol{A}-\boldsymbol{D}$ and $\boldsymbol{E}(\mathrm{P} 15)$ were counterstained with hematoxylin (blue), whereas sections in $\boldsymbol{E}(\mathrm{P} 28)$ were stained with hematoxylin (blue) and eosin (pink). Scale bars: $\boldsymbol{A}, \boldsymbol{D}$ (P28), $\boldsymbol{E}, 20 \mu \mathrm{m} ; \boldsymbol{D}$ (P35), $50 \mu \mathrm{m} ; \boldsymbol{B}, \boldsymbol{C}, 200$ $\mu \mathrm{m}$. normalization, respectively. The following set of primers and oligonucleotides were used: for RT-PCR, Wdr81, CGCCTGCTGACATCTTGTTA and GGGCAGGTACTGGTAGGTGA; Cyclophilin, ATATGAAGGTGCTCTTCGCCGCCG and CATTGGTGTCTTTGCCTGCATTGGC. For qRT-PCR, Wdr81 primers, CGACCCTCATGGACATTCTGC and TGGGGAACCCTGTGACGAAG; Wdr81 probe, CCACGAGGTCTTGCTGCCTGTGCT; Gapdh primers, CTCAACTACATGGTCTACATGTTCCA and CCATTCTCGGCCTTGACTGT; and Gapdh probe, TGACTCCACTCACGGCAAATTCAACG.

Cell culture. HEK 293 cells (ATCC) were grown in DMEM with 1\% glutamine, $1 \%$ penicillin-streptomycin, and 10\% FBS (Invitrogen) at $37^{\circ} \mathrm{C}$ in humid air containing $5 \% \mathrm{CO}_{2}$. The cells were either transfected (Lipofectamine and Plus reagents, Invitrogen) with a plasmid encoding the WDR81 isoform 2 protein in the pTarget mammalian expression vector (Promega) or with pMAX-GPF vector (Amaxa), or were mocktransfected. Immediately after transfection, the cells were cultured in the presence or absence of tunicamycin $(2 \mu \mathrm{g} / \mathrm{ml})$ for $24 \mathrm{~h}$.

Western blotting. Cerebellar tissues were harvested from P21 $W d r 81^{\text {nur } 5}$ homozygous and heterozygous mice and adult (P40) wildtype mice, and the samples were further processed as previously described (Traka et al., 2008). For mitochondrial protein isolation from P21 mouse cerebellar tissues, we used the Mitochondria Isolation Kit for Tissue (Thermo Scientific-Pierce). 


\section{Results}

Adult-onset Purkinje cell loss in the nur5 mouse mutant

The autosomal recessive ENU-induced mouse mutation nur5 (Kile et al., 2003) was identified by the presence of a quivering gait in homozygous mutant mice at approximately P60, whereas their heterozygous littermates looked normal. Gait analysis using ventral plane videography (DigiGait) in P21 (young) and P60 (adult) mice showed significant differences in 8 hindlimb gait indices between the nur5 homozygous (mutant) and heterozygous (control) mice at P60 (Table 1 and 2), whereas no significant differences were found at P21 (data not shown). The P60 nur5 mutants take shorter and more frequent steps and showed an increased variability of the stance width and the paw area between strides (Table 1 and 2), strongly indicating the presence of an ataxic phenotype.

Immunostaining of cerebellar sections for the Purkinje cell marker calbindin revealed that mutant Purkinje cells develop normally before P21 (Fig. $1 A$ ) but start dying soon afterward, as evidenced by the appearance, at P28, of gaps in calbindin staining in the molecular layer of the cerebellar anterior zone cortex (Fig. 1A). Quantitative analysis of the calbindin-positive cells confirmed that Purkinje cell numbers were significantly reduced in the mutants (Fig. $1 F$ ). Purkinje cell loss is patterned (Fig. 1B) and advances with age in nur5 mutants (Fig. 1C), correlating with the progressive ataxic phenotype observed in these mice. TUNEL staining showed that Purkinje cells are undergoing cell death in nur5 mutants at P28 (Fig. 1D), whereas prominent granule cell loss was observed at P35 (Fig. 1D). Consistently, counts of the TUNEL-positive nuclei in the Purkinje cell layer were significantly increased in the nur5 mutants at P28 (Fig. 1G). Purkinje cell death intensifies at P32, when numerous dying cells were found in the Purkinje cell layer but not in the granule cell layer (data not shown).

In addition to ataxia symptoms, the aging nur5 mutants developed a noticeable shrinkage of the eye. TUNEL staining of retinal paraffin sections revealed many dying cells in P15 nur5 mutants, primarily in the outer nuclear layer (ONL; Fig. $1 E$ ) that contains the nuclei of the rod and cone photoreceptors, indicating photoreceptor cell loss. As a result, by P28 the retina becomes much thinner in nur 5 mutants compared with wild-type animals (Fig. 1E). Cell counts confirmed increased TUNEL-positive cells (Fig. 1G) and fewer photoreceptor cells in the ONL of the P15 nur5 mutants (Fig. $1 F$ ).

\section{Nur5 is a mutant allele of the $W d r 81$ gene}

Gene mapping using linkage analysis with simple sequence length polymorphism markers enabled us to position the mutation between the D11DIE39 and D11Mit245 markers, a region that contains the $W d r 81$ gene (Fig. $2 A$ ) among a total of 115 known genes (NCBI Mus musculus genome Build 37.1). We identified a T to C transition at coding nucleotide 4046 in exon 4 of the $W d r 81$ gene in nur 5 mutants (Fig. $2 B$ ). No base pair changes were identified in any of the coding regions of the remaining critical region genes, nor was the sequence change identified in $W d r 81$ found in a screen of 25 other mouse strains. We confirmed that nur5 is a mutant allele of the $W d r 81$ gene ( $W d r 81^{\text {nur } 5}$ ) by rescuing the Purkinje cell and photoreceptor cell loss in P60 nur5 mutants that were carriers of the BAC transgene $\mathrm{Tg}$ (MSMG01-261K4)12Pop (Tg-nur5/nur5), which contains a copy of the wild-type Wdr81 gene (Fig. 2C). Counts of the calbindin-positive cells confirmed that nur5 mutants had undergone severe Purkinje cell loss at P60, whereas no cell loss was observed in their nur5 heterozygous and Tg-nur5/nur5 littermate mice compared with age-matched wild-
WDR81

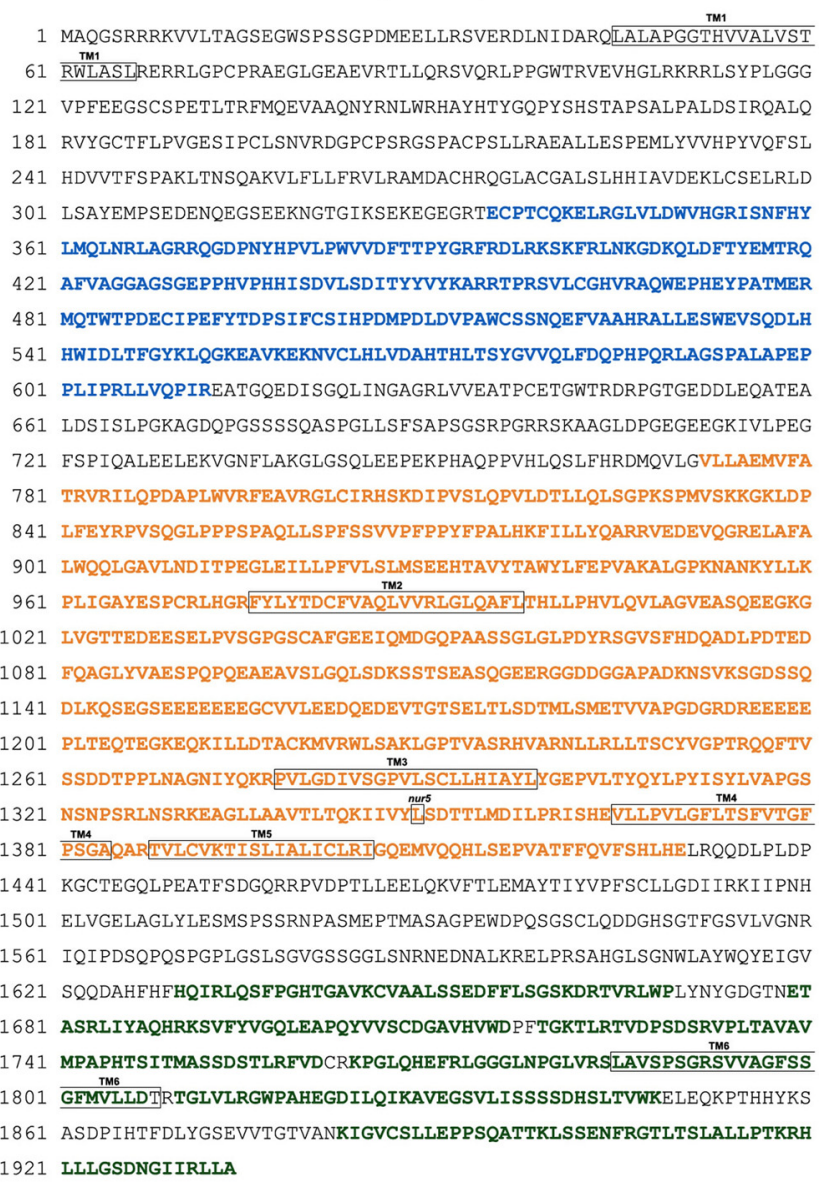

Figure 3. WDR81 protein domain prediction. The WDR81 protein (isoform 1) consists of 1934 amino acids and contains a BEACH (Beige and Chediak-Higashi) domain at the $\mathrm{N}$ terminus (335-612, blue), a MFS domain (772-1430, orange), and six WD repeats (green) in its C terminus. The predicted six transmembrane domains (TM1-TM6) are outlined by boxes. The nur 5 mutation produces an $L$ to $P$ amino acid substitution at position 1349 , which is outlined by a box in the MFS domain.

type mice (Fig. 2D). Likewise, counts of the nuclei in the ONL confirmed the rescue of the photoreceptor cell loss in the Tgnur5/nur5 mice (Fig. 2D). Furthermore, the rescued mice appeared phenotypically normal, were free of both ataxia and tremor symptoms, and showed no weight loss or motor defects on the accelerating rotarod test, in contrast to their nur 5 homozygous littermates (Fig. 2E).

The longest WDR81 isoform in the mouse is predicted to be $\sim 211 \mathrm{kDa}$, contains 1934 amino acids, and is composed of a $\mathrm{BEACH}$ (Beige and Chediak-Higashi) domain at the $\mathrm{N}$ terminus (335-612) and six WD repeats in its $C$ terminus according to the Ensembl genome database and cross references to outside databases (PROSITE and SMART). The nur5 mutation results in a L1349P amino acid substitution in the MFS domain of the WDR81 protein (orthologous to human isoform 1; Fig. 3) predicted by the CLCMain Workbench version 6.6 software (CLC bio), and the mutated amino acid is conserved among human, bovine, and mouse. The MFS domain is present in transmembrane solute transporters, which are capable of carrying small molecules in response to chemiosmotic ion gradients (Pao et al., 1998). Analysis with the TMpred software (www.ch.embnet. org/software/TMPRED_form.html) predicts WDR81 to be a transmembrane protein with six membrane-spanning domains 
A

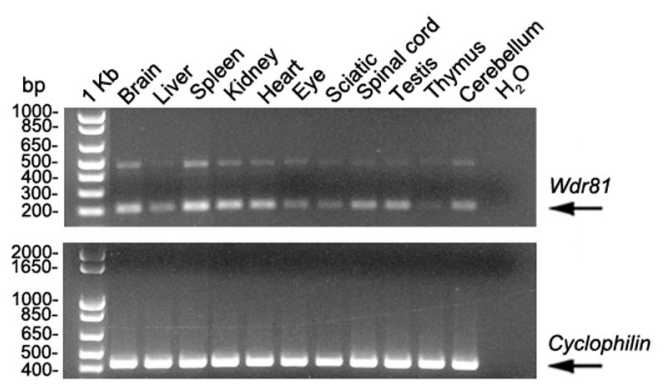

C
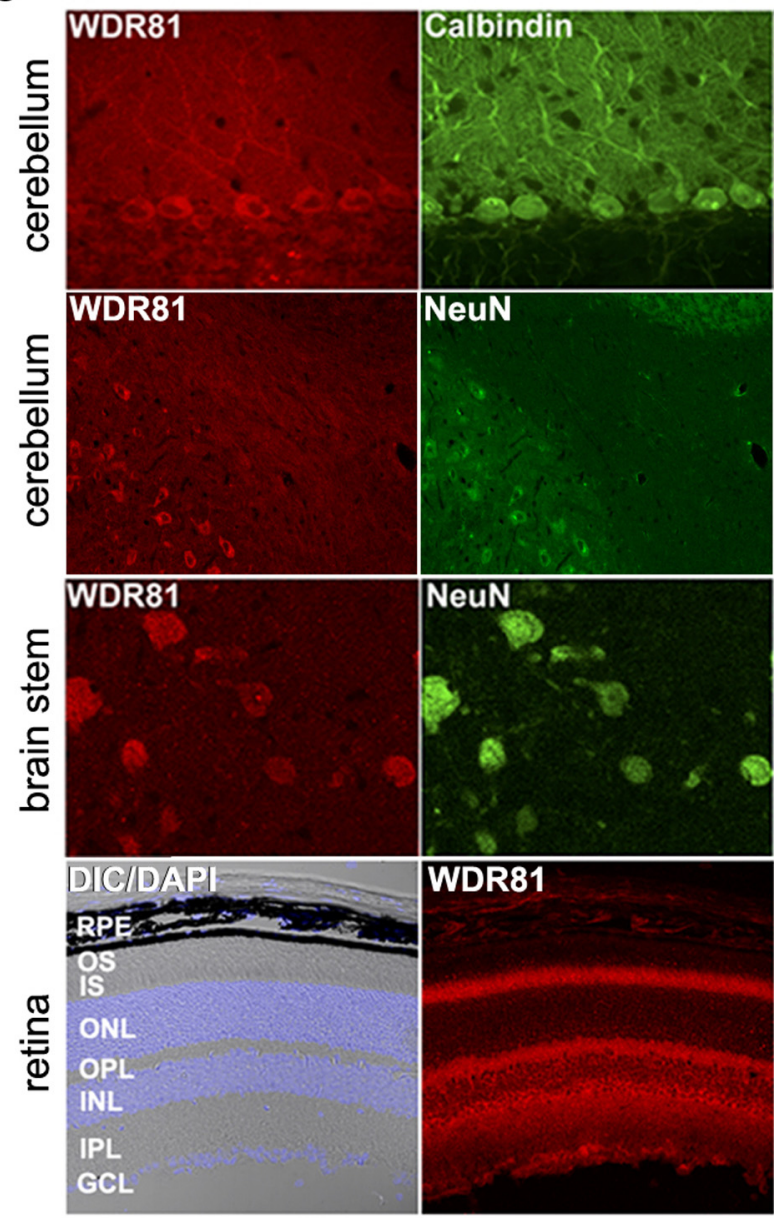

Figure 4. Expression analysis of Wdr81 in the CNS. A, The 201 bp Wdr81 CDNA product is expressed in the CNS (brain, spinal cord, cerebellum), PNS (sciatic nerve), and all peripheral organs of adult wild-type mice, as determined by RT-PCR analysis using a set of primers that span the intron 2-3 of the Wdr81 gene. Sequencing analysis confirmed that the higher band at $460 \mathrm{bp}$ is the result of contamination with genomic Wdr81 DNA. The first lane shows the $1 \mathrm{~kb}$ DNA ladder (Invitrogen). Amplification of the cyclophilin gene product at $450 \mathrm{bp}$ was used for the normalization of the mRNA levels in each sample. $\boldsymbol{B}$, Expression of the WDR81 protein is detected at $\sim 90$ and $80 \mathrm{kDa}$ on Western blots of cerebellum, brain, and spinal cord extracts isolated from adult wild-type mice, whereas it is absent from thymus, which was used as a negative control tissue. Actin was used for the normalization of protein levels. C, Within the cerebellum, immunostaining shows that WDR81 (red) colocalizes with calbindin (green) in the Purkinje cell dendrites and somata and in the neurons of the deep cerebellar nuclei labeled by the neuronal marker NeuN (green). In the brainstem, WDR81 (red) is expressed by neurons stained for NeuN (green). WDR81 (red) is also present in different cell layers across the retina. Overlay of WDR81 staining (red) with DAPI staining (blue) and differential interference contrast (DIC) microscopy images demonstrates that WDR81 is localized to the IS, OPL, INL, IPL, and GCL layers. RPE, Retina pigment epithelium; OS, outer segment layer; IS, inner segment layer; ONL, outer nuclear layer; OPL, outer plexiform layer; INL, inner nuclear layer; IPL, inner plexiform layer; $\mathrm{GCL}$, ganglion cell layer. Scale bars: $\boldsymbol{C}$ (cerebellum), $25 \mu \mathrm{m}$; $\boldsymbol{C}$ (brainstem, retina), $75 \mu \mathrm{m}$.
(Fig. 3). Recently, the missense mutation P856L was found in exon 1, which also lies in the MFS domain of WDR81 isoform 1, in individuals suffering from CAMRQ2 (Gulsuner et al., 2011), a condition that involves cerebellar hypoplasia and cerebellar ataxia similar to the $W d r 81^{\text {nur } 5}$ phenotype.

\section{Wdr81 is expressed in Purkinje cells and photoreceptors}

We found that $W d r 81$ mRNA is expressed in almost all of the tissues of adult wildtype mice analyzed by RT-PCR, including all CNS regions examined (Fig. 4A). Additionally, a polyclonal antibody raised against WDR81 amino acids 1495-1551 recognizes two bands, $\sim 90$ and $80 \mathrm{kDa}$ in size, in cerebellum, brain, and spinal cord extracts isolated from adult wild-type mice (Fig. 4B). The $90 \mathrm{kDa}$ band likely corresponds to isoform 2 (predicted $\sim 96$ $\mathrm{kDa}$; orthologous to human isoform 2), which results from translation initiation at a start codon downstream of that of isoform 1 and therefore has a shorter $\mathrm{N}$ terminus than isoform 1 . The $80 \mathrm{kDa}$ band may correspond to isoforms 3 (predicted $\sim 80 \mathrm{kDa}$; orthologous to human isoform 3 ) and/or 4 (predicted $\sim 77 \mathrm{kDa}$; orthologous to human isoform 4). Nevertheless, we were not able to detect a band at $\sim 211$ $\mathrm{kDa}$ in all the CNS tissues examined (Fig. $4 B$ ), suggesting that isoform 1 is either not expressed in the mouse or undergoes proteolytic processing that removes the region encompassing the amino acid sequence recognized by our antibody.

Using immunohistochemisty, WDR81 was detected in the cerebellar cortex, where it colocalized with the Purkinje cell marker calbindin (Fig. 4C). WDR81 also appeared to be expressed in the neurons of the deep cerebellar nuclei (Fig. 4C) and the brainstem (Fig. 4C), which were identified by staining for the neuronal specific marker NeuN. Immunostaining for WDR81 in the retina of adult wild-type mice showed that the protein signal is present in the inner segment layer of photoreceptors, as well as in other retinal layers (Fig. 4C). The antigen specificity of the anti-WDR81 immunostaining was confirmed by observation of the loss of WDR81 signal from brain and spinal cord extracts (Fig. 5A) as well as from cerebellum, brainstem, and retina sections after blocking the antibody with the immunization peptide (Fig. 5B). We further confirmed the specificity of the WDR81 antibody by showing that it recognizes a band at $\sim 100 \mathrm{kDa}$ in HEK cells transfected to express mouse WDR81 isoform 2 (Fig. 5C). 
A

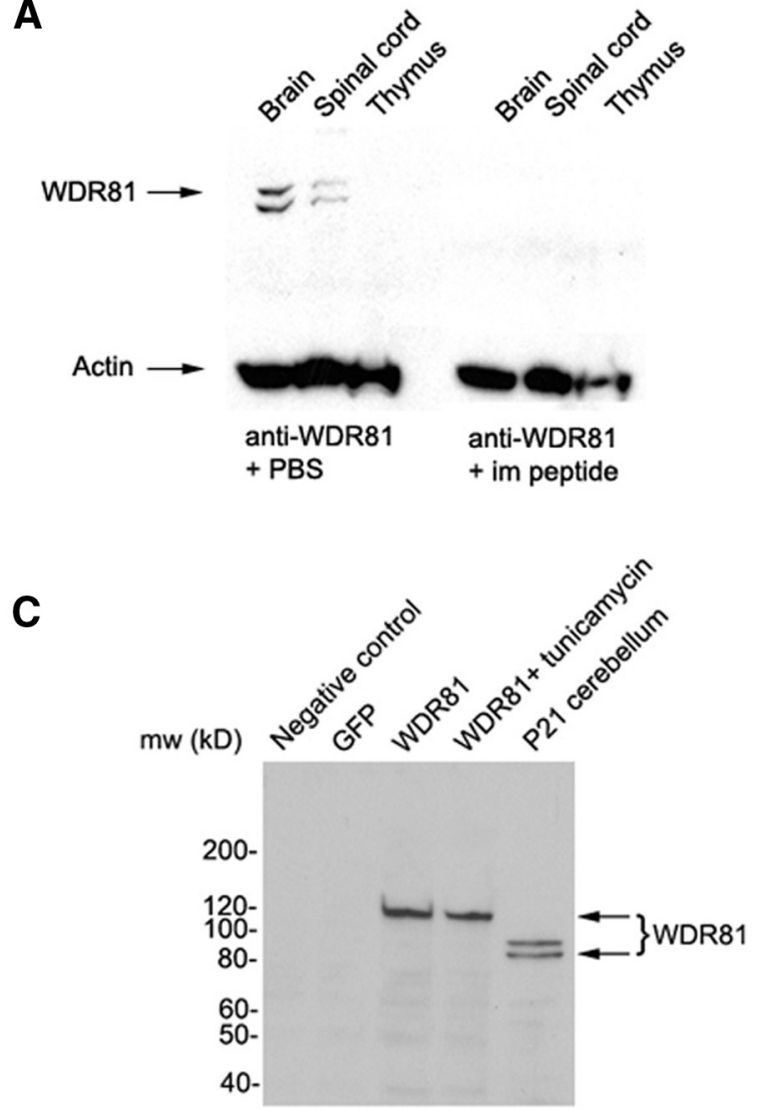

B
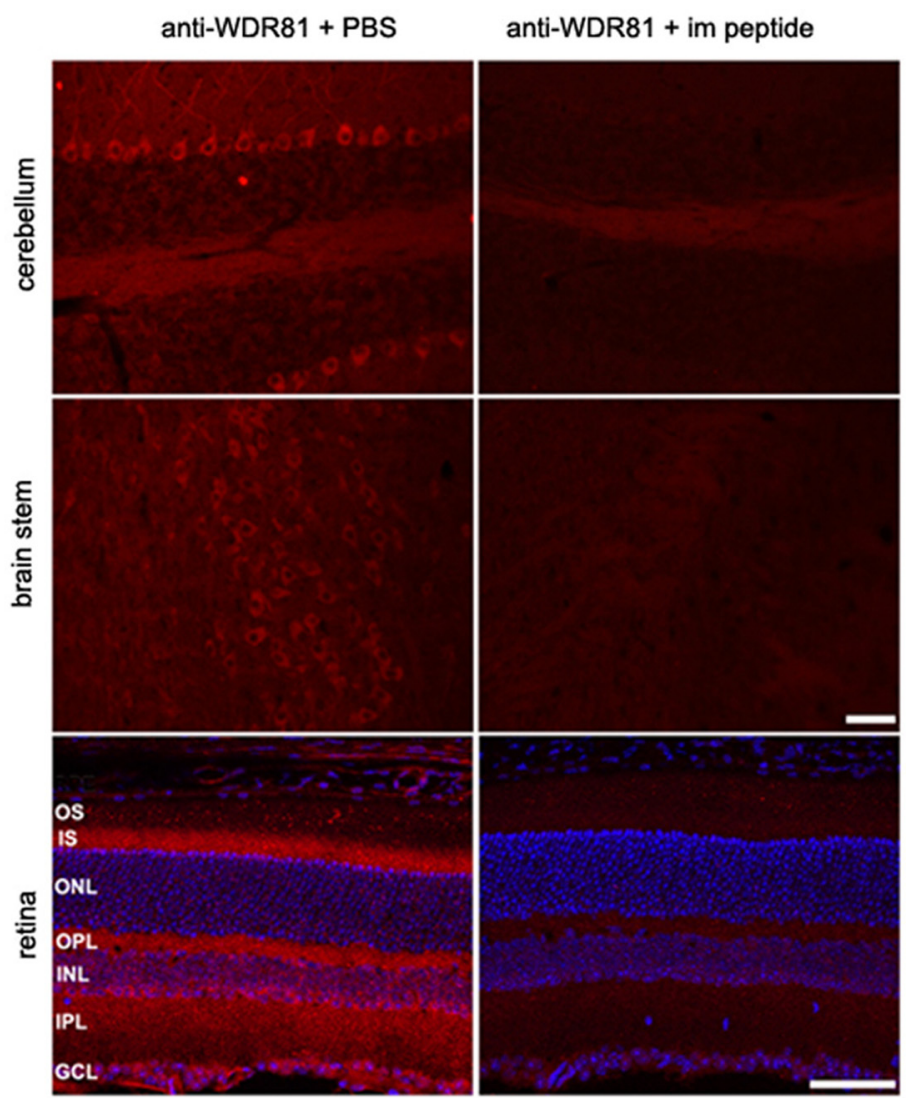

anti-WDR81 + im peptide
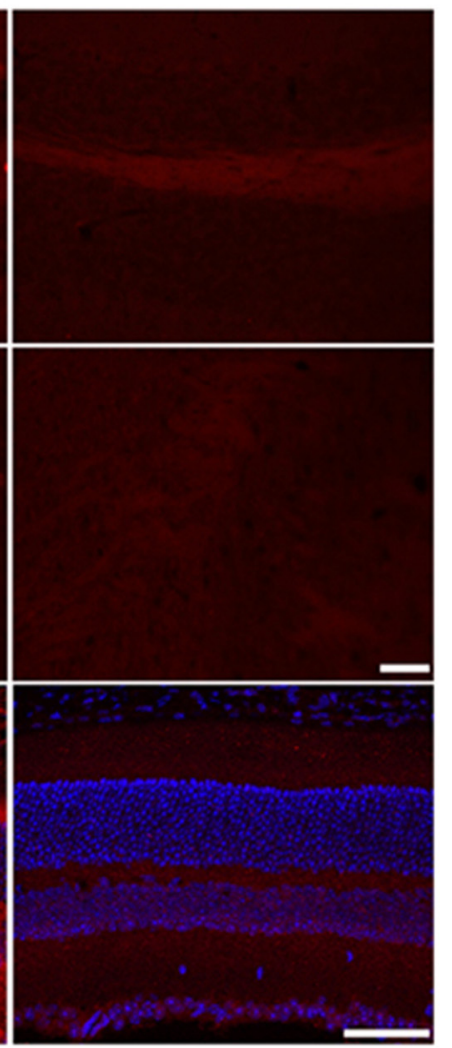

Figure 5. Specificity of the WDR81 antibody for the antigen. Preincubation of the WDR81 antibody with the immunization (i.m.) peptide abolished the detection of WDR81 protein on Western blots of brain and spinal cord extracts $(\boldsymbol{A})$, as well as in immunostained (red) Purkinje cell neurons of the cerebellum $(\boldsymbol{B})$, in brainstem neurons $(\boldsymbol{B})$, and in the retina cell layers $(\boldsymbol{B} ; \mathrm{IS}, \mathrm{OPL}, \mathrm{INL}$, IPL, $\mathrm{GCL}$ ) of adult wild-type mice. Retinal cell nuclei were visualized by DAPI counterstaining (blue). In control experiments, the detection of WDR81 protein is not affected by the preincubation of the WDR81 antibody in 1X PBS. C, The WDR81 antibody recognizes a band at $\sim 100 \mathrm{kDa}$ in protein extracts of HEK cells transfected with a plasmid that encodes the isoform 2 of the mouse WDR81 protein, which is absent in mock-transfected (negative control) and GFP-transfected HEK cells. The presence of the glycosylation inhibitor tunicamycin in the cell medium does not reduce the molecular weight of the protein. WDR81 is detected at lower molecular weights ( 90 and $80 \mathrm{kDa}$ ) in P21 cerebellar extracts. Actin was used for the normalization of protein levels, and thymus was used as negative control tissue in the Western blots shown in $A$. OS, Outer segment layer; IS, inner segment layer; ONL, outer nuclear layer; OPL, outer plexiform layer; INL, inner nuclear layer; IPL, inner plexiform layer; $\mathrm{GCL}$, ganglion cell layer. Scale bars: $\boldsymbol{B}$ (cerebellum and brainstem), $50 \mu \mathrm{m} ; \boldsymbol{B}$ (retina), $75 \mu \mathrm{m}$.

Wdr81 expression is not likely affected by the $W d r 81^{\text {nur } 5}$ mutation because Wdr81 ${ }^{\text {nur5 }}$ mutant and wild-type mice demonstrated comparable $W d r 81$ mRNA levels in the cerebellum by real-time qRTPCR analysis (Fig. $6 A$ ) and both genotypes showed similar expression patterns of the WDR81 protein in the cerebellum (Fig. $6 B, C$ ) as well as in the retina (Fig. 6C) at P21.

\section{Abnormal mitochondria in the Purkinje cell dendrites of Wdr81 ${ }^{\text {nur } 5}$ mutants}

To obtain insight into the pathological mechanism of Purkinje cell death in $W d r 81^{\text {nur } 5 / n u r 5}$ mutants, we performed TEM analysis of the Purkinje cell defects at P21, before the onset of Purkinje cell loss. This approach revealed that the mutant Purkinje cells contain large, electron dense, spheroid-like structures in the dendrites (Fig. 7B), which were not detected in control Purkinje cells. At higher magnification, these structures were recognized as aberrant mitochondria that showed either a mild (Fig. 7C), or a moderate (Fig. $7 D$ ) to severe (Fig. $7 E$ ) disorganization of cristae (Fig. $7 C-E$ ) and frequently also exhibited an incomplete, or in some cases, absent outer membrane (Fig. $7 C-E$ ). The mitochondrial origin of these abnormal structures was further supported by immunogold detection of the mitochondrial marker COX IV (Fig. 7F, G).
To determine the extent of the mitochondrial abnormalities in the mutant Pukinje cells, we used 3DEM analysis (serial blockface scanning EM). EM images of serial sections were acquired from cerebellar slices of control $\left(W d r 81^{\text {nur } 5 /+}\right)$ and mutant $\left(W d r 81^{\text {nur } 5 / \text { nur } 5}\right.$ ) mice at $\mathrm{P} 21$, and individual mitochondria within five randomly selected Purkinje cell dendrites were traced and analyzed in each mouse. In both genotypes, the majority of mitochondria had an elongate, cigar-shaped morphology in single EM images (Fig. $8 A, B$ ) but a small percentage of control (Fig. $8 A ; 4.8 \%$ ) and mutant (Fig. $8 B, C ; 5.5 \%$ ) mitochondria had an aberrant spheroid-like morphology that included cristae disorganization and a frequently disrupted outer membrane at higher magnification (Fig. 8C). When reconstructed in 3D (Fig. 8D,E), the aberrant mitochondria in the mutant mouse were readily distinguishable by their spherical shape and increased size (Fig. $8 E$, red) compared with the normal tubular mitochondria common in control (Fig. $8 D$, green) and mutant mouse (Fig. $8 E$, green). Volumetric comparisons of the total mitochondrial pool in each genotype revealed slightly increased diameters (Fig. $8 H, I$ ) and reduced surface to volume ratio (Fig. $8 J$ ) in the mutant. When aberrant mitochondria were segregated for analysis, aberrant mitochondria in the mutant mouse were $\sim 5$ times 
A

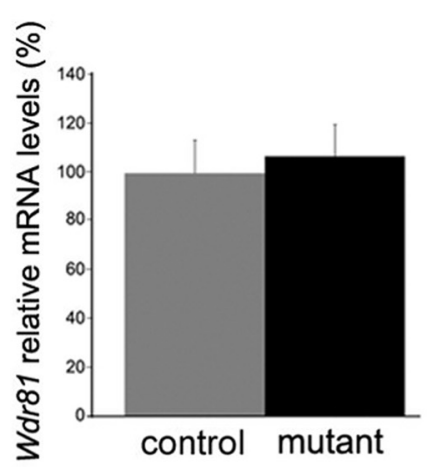

B

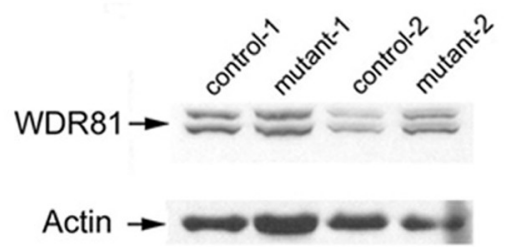

C
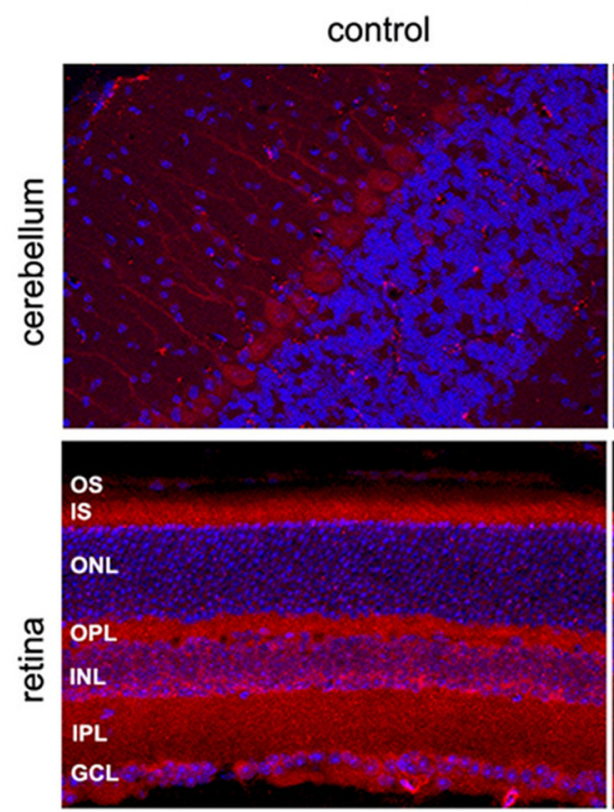

WDR81/DAPI
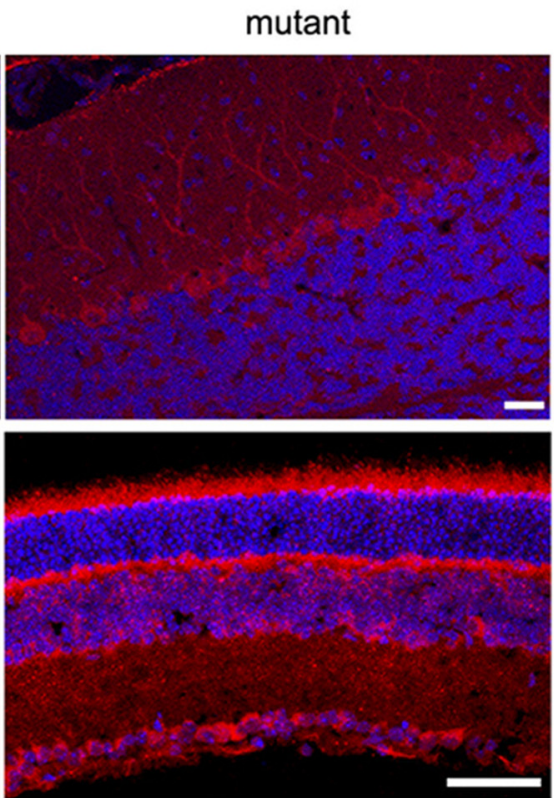

Figure 6. Normal expression pattern of WDR81 in the CNS of Wdr81 ${ }^{\text {nur } 5}$ mutants. $\boldsymbol{A}$, Wdr81 mRNA is expressed at normal levels in the cerebellums of Wdr8 $1^{\text {nur } 5}$ (mutant) mice at P21 compared with control mice (age-matched wild-type mice, mean \pm SD; $n=3$ mice per genotype). $p>0.05$ (two-tailed unpaired Student's $t$ test). $\boldsymbol{B}$, WDR81 is expressed at the same level in mutant and control cerebellar protein extracts. $C$, The expression pattern of WDR81 (red) in the cerebellum and the retina is similar between mutant mice and controls at P21. Sections were counterstained with DAPI (blue) to visualize nuclei. Actin was used for the normalization of protein levels in the Western blot shown in $\boldsymbol{B}$. OS, Outer segment layer; IS, inner segment layer; ONL, outer nuclear layer; OPL, outer plexiform layer; INL, inner nuclear layer; IPL, inner plexiform layer; GCL, ganglion cell layer. Scale bars: $\boldsymbol{C}$ (cerebellum), $25 \mu \mathrm{m}$; $\boldsymbol{C}$ (retina), $75 \mu \mathrm{m}$.

wider (Fig. $8 H$ ) and represented the outliers in the total population (Fig. 8I). Although approximately the same length as other mitochondria (Fig. $8 F$ ), aberrant mitochondria in the mutant mouse were $\sim 5$ times greater in volume than normal mitochondria (Fig. 8G). Aberrant mitochondria in the mutant mouse were not distended or vacuolated, which might otherwise have accounted for their size, suggesting that the increased volume was the result of mitochondrial fusion or aggregation. As they were more spherical, aberrant mitochondria also exhibited reduced surface to volume ratio (Fig. 8J) compared with controls.

\section{WDR81 is localized in mitochondria}

The finding of mitochondrial abnormalities in the nur5 mutant Purkinje cells prompted us to examine the subcellular localization of WDR81 by immunoelectron microscopy and subcellular fractionation analysis of the cerebellum. Our data showed the presence of the WDR81 signal in dendritic mitochondria (Fig. 9Aa) and mitochondrial-enriched fractions (COX IV positive; Fig. 9C) of $W d r 81^{\text {nur5/+ }}$ (control) mice, suggesting that WDR81 most likely localizes in mitochondria of Purkinje cells. Preincubation of the antibody with the immunization peptide significantly reduced the WDR81 signal in mitochondria, indicating the antigen specificity of the anti-WDR81 immunostaining (Fig. $9 A b)$. Moreover, we found that the L1349P mutation does not prevent the targeting of WDR81, as it was correctly localized in normal-looking mitochondria of the $W d r 81^{\text {nur } 5 / \text { nur5 }}$ (mutant) mice (Fig. 9Ba) as well as in mitochondria-enriched fractions (Fig. 9C). Additionally, the mutant mice showed WDR81 signal localization in aberrant-looking mitochondria (Fig. 9Bb).

\section{Discussion}

Recently, the missense mutation P856L was identified in the longest isoform of the WD-repeat containing protein WDR81 in members of a large consanguineous family in Turkey suffering from CAMRQ2 (Gulsuner et al., 2011), a condition that involves cerebellar hypoplasia, cerebellar ataxia, severe mental retardation, and quadrupedal locomotion. Neuro-ophthalmic findings and atrophy of the central region of the retina (macula) have also been reported in two CAMRQ2 patients from the same family (Sarac et al., 2012). Nevertheless, the role that this protein plays in the CNS remains unknown. Here, we provide evidence that a WDR81 missense mutation, L1349P, causes adult-onset and progressive Purkinje cell death as well as early-onset photoreceptor cell loss in the ENU-induced mouse mutant line nur5. Because the Wdr $81^{\text {nur } 5}$ mutant demonstrates cerebellar ataxia and cerebellar atrophy, as well as retinal degeneration similar to the human disease, it is a critical mouse model for dissecting the pathogenic mechanism of the WDR81 mutation in CAMRQ2.

We also demonstrate that mouse WDR81, which is predicted to be a transmembrane protein, is expressed in Purkinje cells like its human counterpart (Gulsuner et al., 2011), as well as in photoreceptor cells and other neurons in the brain and the retina. We also provide evidence that WDR81 is likely localized in Purkinje cell mitochondria and that the L1349P amino acid substitution neither affects the WDR81 expression pattern in Purkinje cells and photoreceptor cells nor disrupts the targeting of the protein to mitochondria. Compared with leucine, proline is less hydrophobic, and because the $\alpha$ amino group cannot form hydrogen bonds, it cannot stabilize $\alpha$ helices or $\beta$ sheets (Petsko and Ringe, 
2004). Additionally, proline can cause distortions in the $\alpha$ helices of membrane proteins by introducing a kink (Cordes et al., 2002). Furthermore, proline significantly affects the kinetics of protein loop formation, which may play an important role early in the folding of the polypeptide chain (Krieger et al., 2005). Therefore, we predict that the L1349P mutation causes conformational changes that disrupt WDR81 protein function in $W d r 81^{\text {nur5 }}$ mutants.

The striking cerebellar pathology observed in CAMRQ2 patients and Wdr81 $1^{\text {nur } 5}$ mutants strongly suggest WDR81 plays an essential role in Purkinje cells; however, its exact function in these neurons remains unknown. Interestingly, both the human and mouse mutations lie in the MFS domain of the protein, which is present in transmembrane solute transporters that carry small molecules in response to chemiosmotic ion gradients (Pao et al., 1998). The WDR81 MFS domain is flanked by a BEACH domain in the $\mathrm{N}$ terminus and six WD repeats in the $\mathrm{C}$ terminus. $\mathrm{BEACH}$ is a highly conserved domain found in proteins involved in diverse biological processes but has no clear function (De Lozanne, 2003). The WD repeats are also present in a broad spectrum of critical eukaryotic proteins with diverse functions (Li and Roberts, 2001); however, they do not have a known functional role and most likely form a propeller structure, which typically provides a platform for protein-protein interactions.

The mechanism of pathogenesis that leads to Purkinje cell death and cerebellar atrophy in CAMRQ2 has not yet been characterized. Here, we used TEM and 3DEM analysis to investigate the pathogenic changes that occur in Purkinje cells of the $W d r 81^{\text {nur } 5}$ mutants before their loss. This approach allowed us to identify significant size and shape changes in a small percentage of dendritic mitochondria of the mutant Purkinje cells. Aberrant mitochondria in the mutant were substantially larger and spherical and likely to be dysfunctional, as the cristae membranes were disorganized and the outer membrane was frequently disrupted. This finding suggests that Purkinje cell loss in the $W d r 81^{\text {nur } 5}$ mutants is preceded by the presence of mitochondrial abnormalities.

Impaired mitochondrial function, because of defects in mitochondrial energy production and mitochondrial dynamics, has been described in a broad spectrum of adult-onset neurodegenerative diseases, including hereditary cerebellar ataxias (Schon and Przedborski, 2011). A high percentage ( $\sim 4 \%$ ) of the genetic loci identified in these diseases are associated with mitochondrial function (Schon and Przedborski, 2011), consistent with the vital role that these organelles play in neuronal survival. Nevertheless, the majority of mitochondria in the $W d r 81^{\text {nur } 5}$ mutants have a control

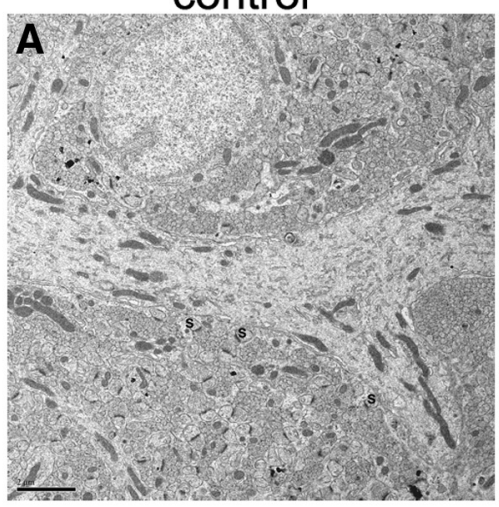

mutant

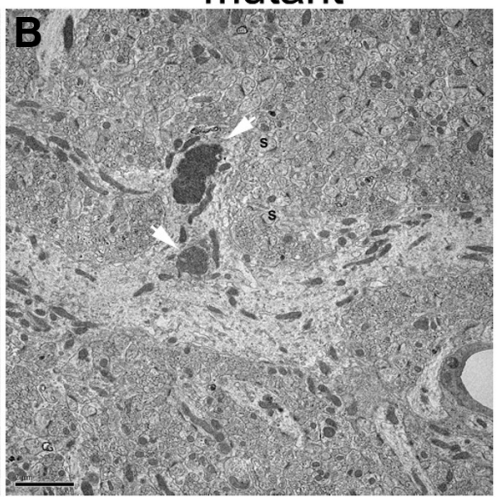

mutant

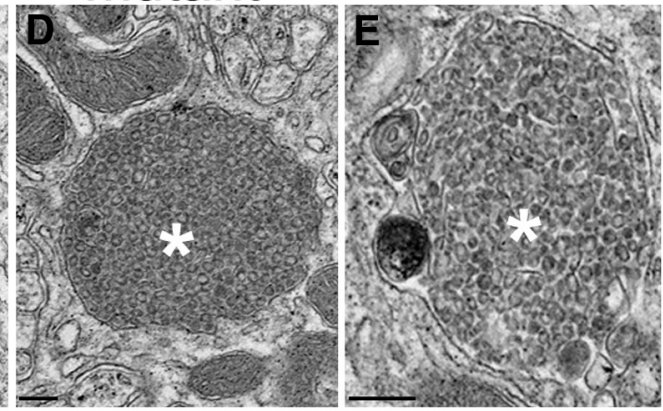

mutant

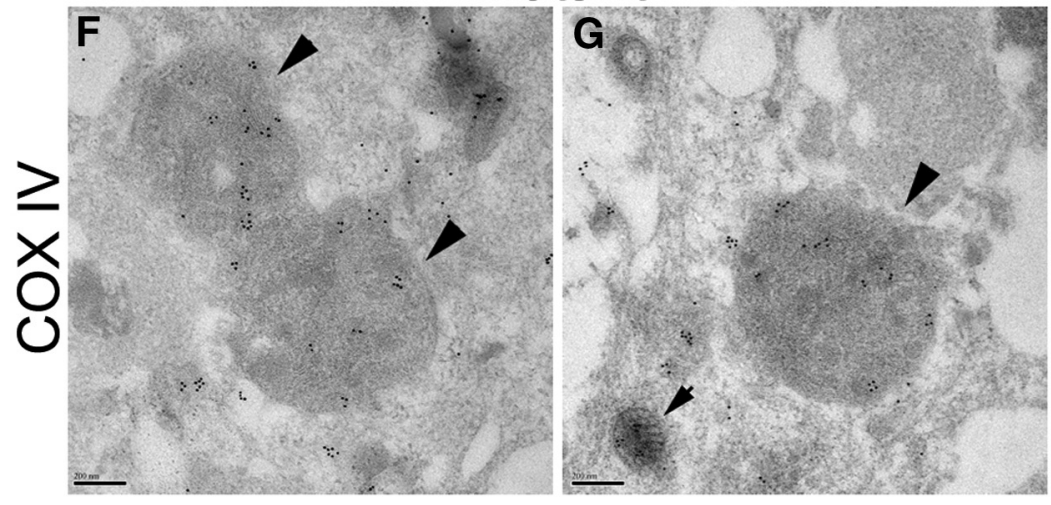

Figure 7. Mitochondrial defects in Wdr81 $1^{\text {nur5 }}$ mutant Purkinje cells. $\boldsymbol{A}, \boldsymbol{B}$, TEM analysis of Purkinje cell dendrites in the $W d r 81^{\text {nur } 5}$ heterozygous (controls) and homozygous (mutant) mice recognized by their association with dendritic spines(s). Large spheroid-like morphology, contained mitochondrial-like cristae with either mild ( $\boldsymbol{C}$, asterisk), or moderate ( $\boldsymbol{D}$, asterisk) to severe , asterisk) disorganization, and had a disrupted outer membrane. Immunoelectron microscopy detected the mitochondria marker COX IV in mitochondrial-like structures $(\boldsymbol{F}, \boldsymbol{G}$, arrowheads) and in normal mitochondria of the mutant Purkinje cell dendrites (G, arrow). Scale bars: $\boldsymbol{A}, 2 \mu \mathrm{m} ; \boldsymbol{C}-\boldsymbol{G}, 200 \mathrm{~nm}$. normal morphology. There are several possible mechanisms by which the presence of a small pool of aberrant mitochondria may contribute to Purkinje cell death. Damage to the inner and outer membranes may allow aberrant cytochrome $c$ release into the cytosol, with direct activation of apoptotic pathways (Galluzzi et al., 2009). Mitochondria also mediate calcium sequestration and regulate reactive oxygen species production, both of which can have catastrophic consequences to the cell when dysregulated (Gleichmann and Mattson, 2011). The subset of clearly aberrant mitochondria might also reflect an extreme example of general mitochondrial abnormalities in the $W d r 81^{\text {nur } 5}$ mutants that result in Purkinje cell loss because of their high-energy demands. Alternatively, the accumulation of large, aberrant mitochondria in the dendrites of mutant Purkinje cells might impede vesicle 

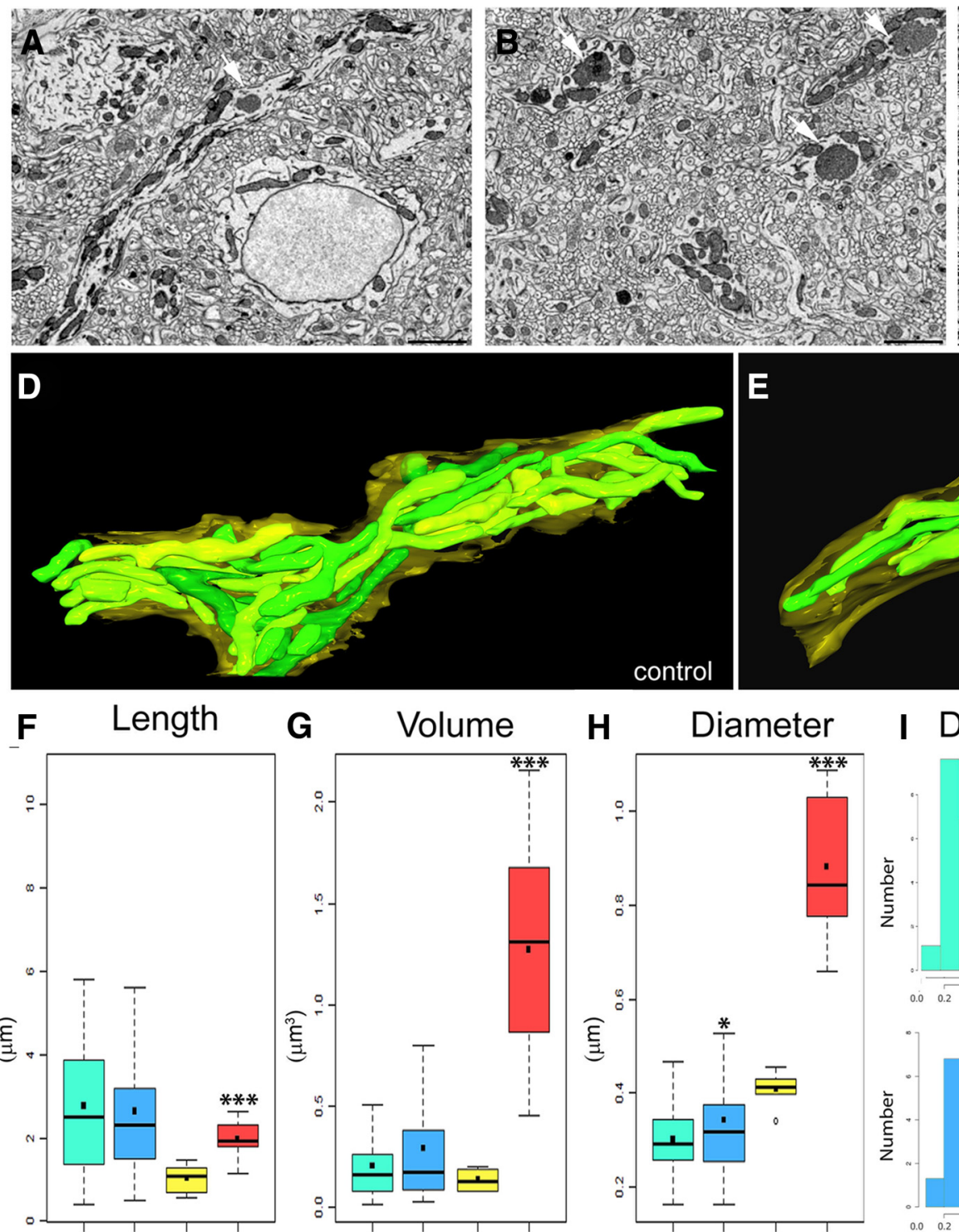

G

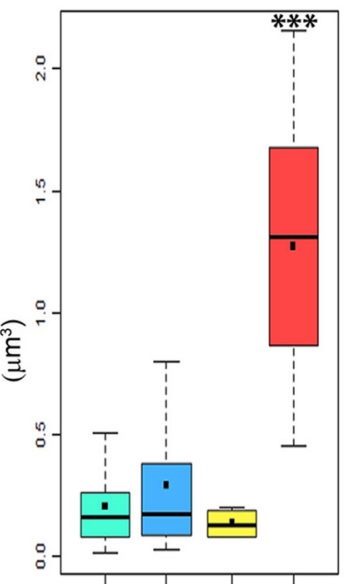

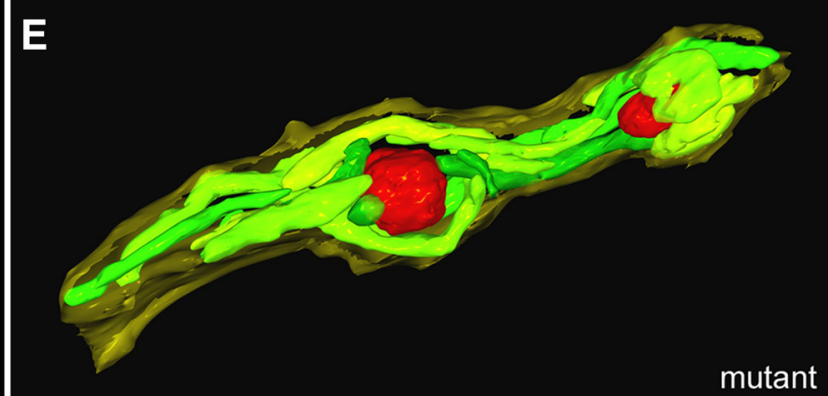

H Diameter

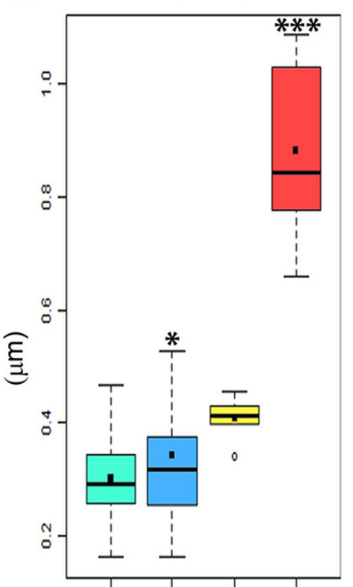

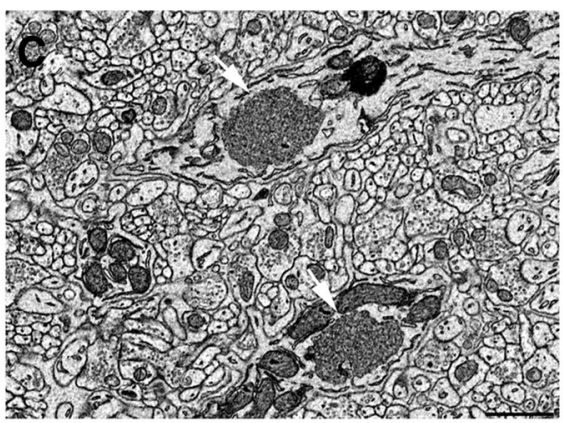

Diameter

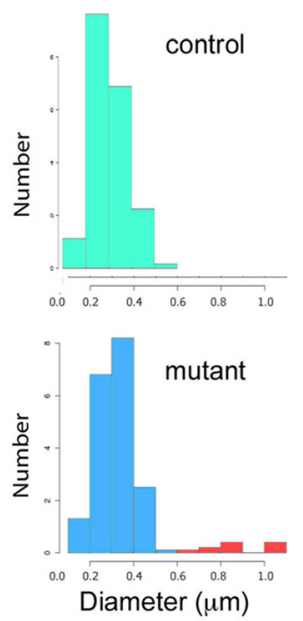

J Surface:Volume

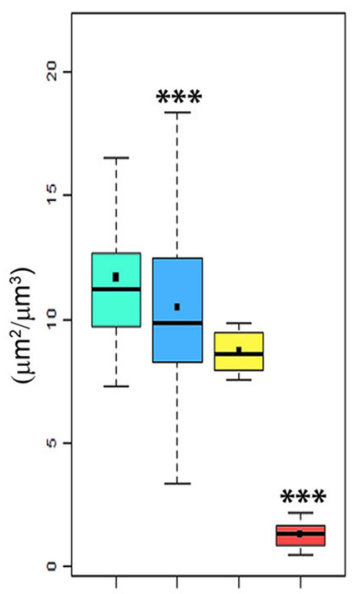

\section{control All mitochondria \\ mutant All mitochondria \\ control Abberant mitochondria \\ mutant Abberant mitochondria}

Figure 8. 3DEM analysis of mitochondria in the Purkinje cell dendrites at P21. Images of ultrathin $(50 \mathrm{~nm}) 3 D E M$ cerebellar sections show numerous normal and a few spheroid-like aberrant mitochondria in $W d r 81^{\text {nurs/+ }}$ (control; $\boldsymbol{A}$, arrows) and $W d r 81^{\text {nurs } / \text { nurs }}$ (mutant; $\boldsymbol{B}$, arrows) dendrites. C, At higher magnification, the mutant aberrant mitochondria (arrows) show disorganized cristae and no outer membrane. Normal tubular mitochondria are detected in 3DEM reconstructed dendrites of the control ( $\boldsymbol{D}$, green) and the mutant $(\boldsymbol{E}$, green) mouse, which also contained large spheroid-like mitochondria (red). Graphs showing the mitochondrial length $(\boldsymbol{F})$, volume $(\boldsymbol{G})$, diameter $(\boldsymbol{H})$, diameter distribution $(\boldsymbol{I}$, histogram), and ratio of the mitochondrial surface area to volume $(J)$ in control and mutant dendrites when the normal mitochondria are included or excluded from the analysis. Box plots showing median (black bar), the $25-75 \%$ (box), mean (black square), and 2.5-97.5\% range (whiskers). Kolmogorov-Smirnov test indicates nonparametric data for all mitochondria: ${ }^{*} p<0.05$ (Wilcoxon signed rank test). ${ }^{* * *} p<0.001$ (Wilcoxon signed rank test). Kolmogorov-Smirnov test indicates normal data for aberrant mitochondria: ${ }^{* *} p<0.001$ (Welch two-sample $t$ test). Scale bars: $\boldsymbol{A}, \boldsymbol{B}, 2 \mu \mathrm{m} ; \boldsymbol{C}, 1 \mu \mathrm{m}$.

trafficking in the somatodendritic compartment, leading to cell death.

In conclusion, in this report, we provide evidence that the nur5 mutant mouse strain, which displays tremor and an abnormal gait, as well as Purkinje cell degeneration and photoreceptor cell loss, is the result of a recessive missense mutation in the Wdr81 gene. Interestingly, a WDR81 mutation has recently also been shown to be responsible for the human autosomal recessive cerebellar ataxia CAMRQ2. In addition, we provide evidence suggesting that WDR81 localizes to Purkinje cell mitochondria and that abnormalappearing mitochondria accumulate in Purkinje cell dendrites in the mutant animals. Further elucidation of WDR81 function in the CNS should lead to a better understanding of the mechanism of pathogenesis observed in $W d r 81^{\text {nur } 5}$ mutants and CAMRQ2. 
A

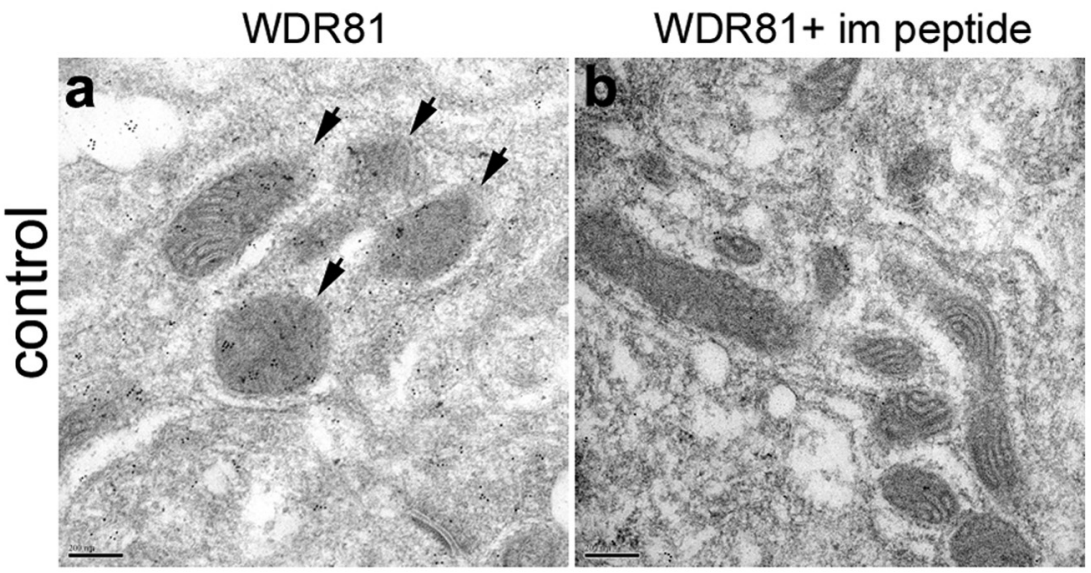

B

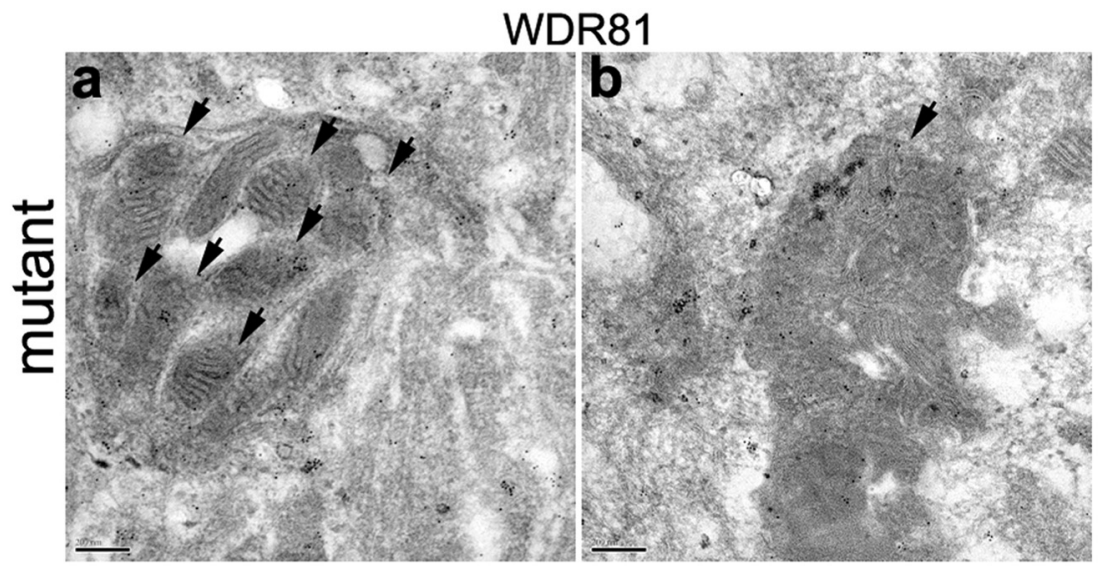

C

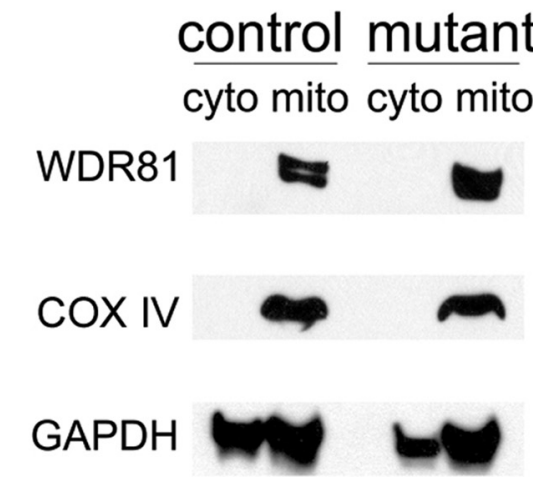

Figure 9. WDR81 is localized in mitochondria. $\boldsymbol{A}$, Immunoelectron microscopy detecting WDR81 on P21 ultrathin cerebellar sections shows localization of the protein in mitochondria of the Wdr8 $1^{\text {nur5/+ }}$ (control) Purkinje cell dendrites ( $\boldsymbol{a}$, arrows). The WDR81 signal was significantly reduced by preincubation of the antibody with the immunization (i.m.) peptide (b). $\boldsymbol{B}$, Normallooking ( $\boldsymbol{a}$, arrows) and aberrant-looking ( $\boldsymbol{b}$, arrow) mitochondria in $W d r 81^{\text {nur } 5 / \text { nur } 5}$ (mutant) Purkinje cell dendrites were stained positive for WDR81. C, Western blot analysis shows that the WDR81 protein is present in mitochondrial-enriched fractions and absent in cytoplasmic-enriched fractions of control and mutant mice. COX IV was used as a positive control for mitochondrial fractions and GAPDH for mitochondrial- and cytoplasmic-enriched fractions. Scale bars: $A, B, 200 \mathrm{~nm}$.
Deerinck TJ, Bushong EA, Lev-Ram V, Shu X, Tsien RY, Ellisman MH (2010) Enhancing serial block-face scanning electron microscopy to enable high resolution 3-D nanohistology of cells and tissues. Microsc Microanalysis 16 [Suppl 2]:1138-1139.

Dupree JL, Coetzee T, Blight A, Suzuki K, Popko B (1998) Myelin galactolipids are essential for proper node of Ranvier formation in the CNS. J Neurosci 18:1642-1649. Medline

Fiala JC (2005) Reconstruct: a free editor for serial section microscopy. J Microsc 218:52-61. CrossRef Medline

Fogel BL, Perlman S (2007) Clinical features and molecular genetics of autosomal recessive cerebellar ataxias. Lancet Neurol 6:245-257. CrossRef Medline

Galluzzi L, Morselli E, Kepp O, Kroemer G (2009) Targeting post-mitochondrial effectors of apoptosis for neuroprotection. Biochim Biophys Acta 1787:402-413. CrossRef Medline

Gleichmann M, Mattson MP (2011) Neuronal calcium homeostasis and dysregulation. Antioxid Redox Signal 14:1261-1273. CrossRef Medline

Gulsuner S, Tekinay AB, Doerschner K, Boyaci H, Bilguvar K, Unal H, Ors A, Onat OE, Atalar E, Basak AN, Topaloglu H, Kansu T, Tan M, Tan U, Gunel M, Ozcelik T (2011) Homozygosity mapping and targeted genomic sequencing reveal the gene responsible for cerebellar hypoplasia and quadrupedal locomotion in a consanguineous kindred. Genome Res 21:1995-2003. CrossRef Medline

Hampton TG, Kale A, Amende I, Tang W, McCue S, Bhagavan HN, VanDongen CG (2011) Gait disturbances in dystrophic hamsters. J Biomed Biotechnol 2011:235354. CrossRef Medline

Kile BT, Hentges KE, Clark AT, Nakamura H, Salinger AP, Liu B, Box N, Stockton DW, Johnson RL, Behringer RR, Bradley A, Justice MJ (2003) Functional genetic analysis of mouse chromosome 11. Nature 425:81-86. CrossRef Medline

Krieger F, Möglich A, Kiefhaber T (2005) Effect of proline and glycine residues on dynamics and barriers of loop formation in polypeptide chains. J Am Chem Soc 127:3346-3352. CrossRef Medline

Li D, Roberts R (2001) WD-repeat proteins: structure characteristics, biological function, and their involvement in human diseases. Cell Mol Life Sci 58:2085-2097. CrossRef Medline

Ohno N, Kidd GJ, Mahad D, Kiryu-Seo S, Avishai A, Komuro H, Trapp BD (2011) Myelination and axonal electrical activity modulate the distribution and motility of mitochondria at CNS nodes of Ranvier. J Neurosci 31:7249-7258. CrossRef Medline

Pao SS, Paulsen IT, Saier MH Jr (1998) Major facili-

\section{References}

Abe K, Yuzuriha M, Sugimoto M, Ko MS, Brathwaite M, Waeltz P, Nagaraja $\mathrm{R}$ (2004) Gene content of the 750-kb critical region for mouse embryonic ectoderm lethal tcl-w5. Mamm Genome 15:265-276. CrossRef Medline

Acevedo-Arozena A, Wells S, Potter P, Kelly M, Cox RD, Brown SD (2008) ENU mutagenesis, a way forward to understand gene function. Annu Rev Genomics Hum Genet 9:49-69. CrossRef Medline

Cordes FS, Bright JN, Sansom MS (2002) Proline-induced distortions of transmembrane helices. J Mol Biol 323:951-960. CrossRef Medline

De Lozanne A (2003) The role of BEACH proteins in Dictyostelium. Traffic 4:6-12. CrossRef Medline tator superfamily. Microbiol Mol Biol Rev 62:1-34. Medline

Petsko GA, Ringe D (2004) From sequence to structure In: Protein structure and function (Lawrence E, Robertson M, eds), pp 1-47. London: New Science

Sarac O, Gulsuner S, Yildiz-Tasci Y, Ozcelik T, Kansu T (2012) Neuroophthalmologic findings in humans with quadrupedal locomotion. Ophthalmic Genet 33:249-252. CrossRef Medline

Schon EA, Przedborski S (2011) Mitochondria: the next (neurode)generation. Neuron 70:1033-1053. CrossRef Medline

Soong BW, Paulson HL (2007) Spinocerebellar ataxias: an update. Curr Opin Neurol 20:438-446. CrossRef Medline 
Tan U (2006) A new syndrome with quadrupedal gait, primitive speech, and severe mental retardation as a live model for human evolution. Int J Neurosci 116:361-369. CrossRef Medline

Traka M, Wollmann RL, Cerda SR, Dugas J, Barres BA, Popko B (2008) Nur7 is a nonsense mutation in the mouse aspartoacylase gene that causes spongy degeneration of the CNS. J Neurosci 28:11537-11549. CrossRef Medline
Traka M, Arasi K, Avila RL, Podojil JR, Christakos A, Miller SD, Soliven B, Popko B (2010) A genetic mouse model of adult-onset, pervasive demyelination with robust remyelination. Brain 133:3017-3029. CrossRef Medline 